\title{
A lily-disease.
}

BY

H. MARSHALL WARD, M.A., F.R.S., F.L.S.;

Fellow of Christ's College, Cambritge; and Professor of Botany in the Forestry

School, Royal Indian College, Cooper's Hill.

With Plates XX, XXI, XXII, XXIII, XXIV.

$F^{\text {OR several years past I have been greatly interested and }}$ puzzled by a certain type of small discoloured spots on
the leaves, stems, and other parts of various plants, and during the summer of $1886 \mathrm{I}$ had frequent opportunities of noticing a particular class of these discolourations in the form of orangebrown and buff specks which appeared on the stems, pedicels, leaves, and buds of the white lily (Lilium candidum) growing in my garden. Some attention was also paid to them by me in 1887.

These spots, similar to those on the bracts in Fig. I, and on the bud in Fig. 2, perplexed me exceedingly for a long time, and it seemed as though they would have to be relegated to the large limbo of apparently inexplicable phenomena which continually present themselves to the working pathologist.

Occasionally I found small tufts of a fungus springing from the spots, but it was doubtful whether this was not a saprophyte. Sections through the spots showed, as a rule, no more than is shown in Fig. 5I, i. e. a depressed area of dead and discoloured cells, but in one or two cases I found what looked suspiciously like a definite mycelium in the dead tissues, as shown in Fig. $5^{2}$.

[Annals of Botany, Vol. II. No. VII. November I888.] 
As time went on it seemed significant that the fungus which made its appearance, when the spotted parts were kept damp for a few days under a bell-jar, always presented the same characters; but as this and other modes of culture led rather to the conclusion that the fungus was saprophytic in nature, nothing further came of the matter at the time beyond the accumulation of a few more drawings and notes - the lilies were spotted, and as with many other cases of spotting on leaves, stems, etc., I could not explain the puzzle. At the end of May and beginning of June this year (1888) the same lilies began to show unmistakable signs of ill-health: the lower leaves shrivelled and died, and leaf after leaf in succession on the flowering shoots went off. By the middle of June the plants were looking very bad indeed, and I recognised the small orange and brown spots on the (still healthy) buds in much greater numbers than ever before, and the problem arose once more-how are the spots produced?

During the wet weather at the end of June many of the buds began to develop mouldy patches, and I soon found that such patches sometimes started from the orange spots already known, or from larger buff-coloured areas-the latter especially on the very damp leaves. By July I, every plant in the bed had greyish mouldy patches on the buds, as shown in Fig. I, and several of the buds were shrivelled and dead, and it was clear that the lilies were in for a severe epidemic disease.

On July Io, I noted the following as the position of affairs. There were 258 flowering stems of Lilium candidum in the garden, and more than 1200 flower-buds on them. Half of these buds were already ruined, and less than 10 per cent. were presentable: in fact the vast majority were in the condition exhibited in Fig. I. Every leaf on the lower parts of the plants was decayed long before, and nearly all the small upper leaves and bracts were spotted and blotched like those in Fig. 1 .

By means of marked specimens, around the eight pedicels 
of which I tied coloured worsted, the following facts were elicited as to the progress of the disease.

A spot like that in Fig. 2 on July 10, had changed to the condition shown in Fig. 3 on the 16 th, and the whole bud was black-brown and rotten (Fig. 4) on July 24. Another bud had three very minute spots on July 8 , and on the I 9 th the bud was beginning to open, the spots having altered little, if at all; on July 24 , this bud opened, and its outer perianth-leaves showed several dirty buff spots; otherwise the flower was a good one. And similarly with others. The normal course of events was that a spot, like that in Fig. 2, enlarged till it became like that in Fig. 3, usually coalescing with others on the same bud, until sooner or later the bud was entirely blackened and shrivelled as in Fig. 4 .

The same course was observed in other organs, especially in the leaves. In all cases it was noticed during the wet weather that a rich growth of a grey mould-like fungus made its appearance on and around the buff-coloured spots, and increased as the bud decayed (Figs. I, 3). To my surprise, this 'mould' turned out to be, not one of the Peronosporeae or any such form known to be a virulent parasite, but a fungus of the kind often called Botrytis or Polyactis-a form I had occasionally observed in previous seasons as a presumable saprophyte, and which is usually regarded as only a saprophyte. Of course the first question to be decided was whether or no the Botrytis had really any causal connection with the spots, or whether it merely followed some other form as a scavenger living on the products of the ravages caused by it. It is true the latter seemed the most probable explanation, but there were some facts against it in the present instance, and as the sequel shows the Botrytis turned out to be a parasite, at any rate in this particular case. Before describing the methods and results which led to this conclusion, however, I will describe the fungus as found growing on and in the lily-buds, and the phenomena presented by it when cultivated in artificial and natural nutritive solutions. 
A vertical section through a badly diseased patch (Fig. 3), or through buds in the conditions shown in Figs. I, 4, shows that the grey mouldiness is due to countless erect branched conidiophores, which burst through the cuticle of the epidermis from the tissues inside, and bear the conidia or spores (Figs. 5, 9). The conidiophores stand off from the surface into the damp air, and usually attain a height of about one to three millimeters : as will be shown later, they may attain much larger dimensions under certain conditions fulfilled in cultures. Each conidiophore bores its way through the walls and cuticle of the epidermis-cells (Figs. 7, 10), grows erect for some time, and then puts forth from two to five or more stout, short branches: meanwhile the main stalk has become septate, and its walls pale sepia-brown in colour. The conidia begin to arise as little peg-like projections from the swollen ends of the branches (Fig. $9 c$ c), the ends of the pegs becoming enlarged and filled out more and more with protoplasm.

In such sections as Fig. 5, taken from buds already thoroughly destroyed by the fungus, the hyphae from which the conidiophores spring are found to occupy every part of the bud : not only are all the lacunae and cell-cavities of the calyx and corolla completely full of mycelium, but the tissues of the anthers and ovary likewise. Between the pollen-grains, between the ovules, and even in the tissues of the latter, are the finer hyphae of the fungus, branching in all directions. Moreover, no traces of distinct cells are to be found, for the hyphae completely occupy the substance of the cell-walls, as well as the cavities, and reduce the whole tissue to an amorphous mass of swollen, brown organic substance, in and through which the mycelium is running; so that, as seen in Fig. 5, the remnant of what was the tissues of the bud now forms a mere discoloured packing, so to speak, between the interwoven hyphae.

Sections through a bud in the state shown in Fig. 3 present a less advanced stage of destruction: the epidermis and subjacent tissues beneath the buff-coloured area are utterly 
destroyed (Fig. 6), but in the green parts around there are no hyphae. From the densely packed hyphae in the epidermis, thin branches descend almost vertically through the tissues below (Figs. 6, 7), and emerge at length through the epidermis of the inside of the perianth-lobe, cross the slight interspace between this lobe (sepal) and the edges of the petals which it overlaps, and so infect the interior of the bud. As I shall have occasion to show later (though I did not know it till after infections had been artificially carried out), the spread of these hyphae is facilitated by the poisoning action of the hyphae on the tissues around them.

Sections through still younger spots, e.g. a little more advanced than Fig. 2, show that the hyphae are as yet entirely confined to the cell-walls (Figs. 55, 56), in the swollen substance of which they are growing and branching in all directions, but especially in a plane parallel to the surface of the organ.

In the neighbourhood of the mycelium, e.g. at the margin of the diseased area in Fig. 3, the cell-walls bounding the lacunae, and those of the epidermis and guard-cells of the stomata, are often found to be swollen and turning brown and granular (Fig. 8). This was a phenomenon which greatly puzzled me until I found that it is due to the action of a soluble ferment excreted by the fungus itself, and which slowly diffuses around and kills the cells.

The mycelium in the tissues is richly-branched, septate, and colourless, excepting that with age the cell-walls assume a pale sepia-tint. The branches which come to the exterior to form conidiophores are also at first colourless: as they grow older the cell-walls quickly turn brownish (Fig. 9), as also do the ripening conidia. All the parts are filled with a dense finegrained or minutely vacuolated protoplasm, in which I have seen no definite nuclei, at any rate with ordinary staining reagents. At the same time, it should be mentioned that no special search for nuclei has been undertaken in detail.

The ripe conidium is of an ovoid form, and usually pale sepia in colour, and very large for a Botrytis; its average size 


\section{4}

Marshall Ward._On a lily-disease.

being about $\frac{1}{50}$ to $\frac{1}{40} \mathrm{~mm}$. long by about $\frac{1}{\pi^{\frac{1}{0}}}$ to $\frac{1}{60} \mathrm{~mm}$. broad. At the slightly narrower end may often be seen the remains of the peg-like sterigma by which it was attached to the conidiophore. As will be shown later these conidia are formed and ripen very rapidly, and they germinate at once in water at even a comparatively low temperature-e. g. $8^{\circ}-10^{\circ}$ C.- provided they have access to air. They are wetted with difficulty at first, but soon absorb water and swell, and the protoplasm is then seen to be nearly homogeneous, with minute brilliant granules here and there.

In Fig. Ir I have drawn the chief stages of germination in water at a low ordinary temperature, such as prevailed this summer. The spore was sown in a hanging drop at II.30 a.m.: at $2.3 \circ \mathrm{p} . \mathrm{m}$. it had commenced to germinate, $a$, its protoplasm becoming frothy, and pushing the cell-wall out at two points as colourless germ-tubes. At 7 p.m. the same day, the terminal germ-tube had grown to about four times its previous length, while the second one remained as a mere protuberance on the side of the conidium and developed no further, Fig. I I $a^{\prime}$. Growth continued during the night, and by 10 o'clock next morning, the germ-tube was about five times as long as the spore, and had put forth a branch, and developed several septa, $a^{\prime \prime}$. The conidium was now almost empty, a large vacuole occupying its interior, $a^{\prime \prime}$, and several vacuoles were formed in the proximal segment of the germtube; otherwise the protoplasm was bright and homogeneous. No further growth occurred, however, as the supply of foodmaterial was now exhausted.

A second example is given in Fig. I2, where it will be seen that the process was quite similar, the second germinal tube attaining a somewhat greater length before ceasing to develop further: and this time it was the terminal hypha which was the weak one.

It is well worth notice how very little food-material is necessary to change the manner of germination in these water-cultures: it has happened in a drop containing two or three conidia, that one has died, and in a few hours it can be 
observed that the hyphae of the others are more vigorousthey have been slightly nourished by the remains of the dead spore.

If the conidia are sown in a drop of suitable culture-fluid, instead of in pure water, the influence of the food-supply makes itself felt from the first moment of germination, as is at once evident on comparing the preceding figures with Figs. $13-16$, and Fig. 32.

The chief difference is that the mycelium grows more rapidly, and of course for a longer time in the nutritive solution; moreover, the germinal hyphae are from the first more numerous, and full of active, brilliant protoplasm, and branch soon and frequently. The septa are also more numerous and close-set. As before, I can describe all the chief phases by reference to a concrete example, drawn at the various stages. The spore shown in Fig. I4 was sown in a drop of Pasteur's solution, where it lay at the edge, at 7 p.m. on July 7 th ; at 10 a.m. on the 8th it had germinated, and put forth the four hyphae exhibited in the drawing. At 7 p.m. on the 8th, i.e. twenty-four hours after sowing, considerable changes had occurred, as shown in Fig. 15. In the first place, the hypha which took the lead in germination has grown but little, and already shows signs of exhaustion, while the two smaller hyphae have practically ceased to develop. All the energy of growth has, in fact, passed into the curved, upper hypha of Fig. 14, and this drawing was selected because it is so easily recognised through the various stages by means of the knee-like curve of the chief hypha. In Fig. I 5 this hypha has grown to many times its former length, has branched considerably, and is full of protoplasm of the peculiar, brilliant, fine-grained, non-vacuolated character which distinguishes actively growing fungi. Only its basal segment is slightly vacuolated, as is also the spore. The particularly one-sided development of this young mycelium is not hard to explain : the spore lay, as said, at the margin of the drop of culture-fluid, and the fortunate hypha with the peculiar kneelike curve at its base happened to be pointing towards the 
central part of the drop, and grew in the direction of abundant food-supply.

By 8.30 a.m. on July 9th, the mycelium had grown too large to be drawn under the higher power, and Fig. 16 shows its relative dimensions under a much lower objective (Zeiss $B$, instead of $\mathrm{D}$ ). The chief changes noticeable are the increased branching, and the formation of certain peculiar cross-connections by the fusion of the tips of lateral hyphae, of which I shall have more to say presently. Three such cross-unions have been formed, as shown at $x$, and these are only the forerunners of many more, as may be seen in Fig. 17, which shows the same mycelium on July IIth, i.e. two days after the last, as far as could be sketched on one plane. As shown by the lines bounding the rectangular area depicted, there are a few leading hyphae which run out beyond the drawing; but these are not important. What is more important, however, is the development of numerous, short, erect hyphae leading up to the lower surface of the cover-slip, and certain others which go down into the depths of the damp-chamber. These hyphae, being at right angles to the general plane of the mycelium, could not be drawn in such a sketch, but I hope to make their conformation and arrangement, etc. intelligible in what follows. Even a glance at Fig. I7 shows that very numerous cross-connections are now established, so that the mycelium has become a real net-work of hyphae; it should also be noted that the general character of the mycelium has now been changed by the development of numerous tufts of thin, sinuous, tendril-like hyphae, chiefly at the ends of lateral branches. Complex as this four-days-old mycelium already is, it is not difficult to trace still the main, stouter branches of the previous stages; these give off branches in all directions, and of many degrees of tenuity. Excepting that several of the larger branches have more numerous septa than before, and that their protoplasm is now more or less vacuolated, and their walls begin to show a tinge of brown, there are no further changes of importance to be noted in Fig. I7. 
We may now pass to the description of some of the details of such a normal mycelium as that exhibited in Figs. I4-17, and first may be taken the shorter branches, which run up more or less at right angles from the main mycelium to the lower surface of the cover-slip, from which the whole culture is suspended; and as I shall have a good deal to say about these peculiar branches, it will be necessary to describe them in some little detail.

The first remarkable fact about them is that they grow vertically, or nearly so, until they come directly in contact with the glass cover-slip, their tips then flatten themselves on the glass surface, and soon afterwards they are found to be sticking to the glass so tenaciously that they cannot be removed without destroying them and their branches. They are clearly the bodies which have been described by $\mathrm{De}$ Bary $^{1}$ as 'Haft-organen,' and I shall therefore term them organs of attachment.

Any one of these organs is developed as follows. A branch rises nearly vertically from the mycelium hanging on the lower free surface of the culture-drop, and its tip swells as it comes in contact with the cover-slip; if the culture-drop is very shallow, these club-shaped branches may meet the glass obliquely from the first.

Soon after contact the organ is seen to have a bright spot at the centre of the attached portion, as shown in Fig. 20 at $x$, and in Figs. 22 and 24. Round this brilliant spot the walls of the hypha, closely pressed to the glass, gradually become thicker (as seen in optical section), and acquire a faint, brownish tinge. It is then seen that the outer contour is surrounded by a glairy film, as shown in Figs. 22 and 24 .

These appearances are not difficult to explain. I have drawn at Fig. 22 the tip of the organ of attachment as it would appear in profile, the double horizontal lines representing the outline of the section of the cover-slip. Viewed from above in the direction of the arrow, we should see a pale,

1 Comp. Morph. and Biol. of Fungi, etc., Engl. ed., p. 45. 
bright spot, because the light meets with least obstruction or deflection at that part; not only is the structure more translucent in that direction, but the neighbouring contents may even be acting, so to speak, as a lens. The glairy film surrounding the organ is deliquescent substance of the cell-wall, the organ being firmly attached by the conversion of part of its walls into a gum-like substance, and I shall shortly demonstrate that this must be due to the action of a ferment excreted by the tips of the hyphae when they come in contact with the glass. When contact is first made these hyphae are full of dense, bright protoplasm; in other words, the strong hyphae are very active. As the walls thicken and stick to the glass, and darken in hue, the protoplasm becomes more and more vacuolated, and may finally be nearly all used up, the changes being very much as in the case of the branches in Fig. 45. Before this, however, the attached organ may branch, at or near the extreme tip (Fig. 24), or further behind; such branching often occurs before attachment, as shown in Figs. 21-25.

It remains to be said that these organs of attachment are not necessarily confined to the vertical branches; for on older cultures, where the air in the damp chamber is kept sufficiently moist, branches growing off from the surface of the hanging drop come in contact with the sides and bottom of the chamber and form just such organs, sometimes in enormous quantities.

These organs may also be much more complex than any figured in the plates, branching repeatedly just below the apices, until, occasionally, a tassel-like tuft of close, short hyphae is formed (Fig. 26), all the tips of the short branches flattening themselves vertically on to the glass. Everything, in fact, points to these organs being of the same morphological nature as those figured by Brefeld in Peziza sclerotiorum $^{1}$, and explained by De Bary subsequently as organs of attachment. 
The next feature of interest in the mycelium is the crossconnections of the hyphae, a phenomenon of constant occurrence in cultures of three or four days old and upwards. As seen in Fig. I 7 these cross-connections may be very numerous, and may occur, so far as I can make out, between hyphae of all orders. The least interesting case is when two hyphae lying nearly parallel and close together simply become joined by cross-branches, as in Fig. I9; but in the same figure I would draw attention to the remarkable case shown at $x$, where a branch, short and thick, coming down from the upper hypha, is met by two small and much thinner ones from the lower one. These two small thin branches have obviously bent over towards a comimon point, the extreme tip, of the larger branch, and then fused with it. But two other little branches have also been developed from the lower hypha, and their ends are also curving over towards the same point, as if to fuse with the large hypha.

It was such cases as this, and some still more remarkable ones which I had observed in another fungus growing on potatoes, which led me to place cultures under continuous observation, so that I could follow this process of conjugation of the hyphae. It is not necessary to describe in detail the precautions and preparations necessary for this: active cultures in hanging drops are placed beneath microscopes, certain branches are fixed in the field of view, and records made from time to time. It is simply a matter of patient observation, aided by a little experience in choosing hyphae likely to emit the conjugating branches before night.

In Fig. 27 is a case which came under notice so to speak accidentally, because $I$ was at the time following the development of the organs of attachment, and was watching the tip of the hypha to that end.

The hypha $a$ was drawn at 7 p.m. on July 18 th. At 6.30 a.m. on the I9th it had grown slowly (the temperature being low) to the extent shown in $b$; $c$ represents the state of affairs at Io a.m. on the same day. At II.40 a.m. on the same day (July 19th) a branch was beginning to develop as a minute 
protuberance, $x$ in $d$, on the lower side of the terminal segment of the main hypha, and from the first this branch was directed towards the second segment of the branch below. At 12.30 this was very distinctly seen to be the case, for the protuberance in question was curved slightly backwards, so that its apex travelled in a line at right angles to the axis of the branch below ; but (as shown in $e$ ) a second protuberance was by this time apparent, springing from the middle segment of the lower branch and with its axis in the same line as that along which the apex of the first one was travelling. At I2.55 (Fig. 27, $f$ and $g$ ) these two protuberances were nearly in contact by their apices; and by 1.10 p.m., as seen in $h$, they had become united, and their protoplasm continuous, the double partition where the tips came in contact having been dissolved away.

As will be seen by referring to Figs. 28, 29, and 30, very similar phenomena are observed in others of the numerous cases of these fusions of small lateral branches (Fig. 30), or of larger terminal ones (Fig. 28), and the next step is to see if any explanation can be offered of this strange process.

It seems to me, after observing numerous cases of these fusions in this and other fungi, that we must distinguish between two steps in the process. In the first place there is some cause at work which determines the formation of a branch, and then, in the second place, we have to assume that some other cause determines the direction in which the branch grows, at least in the cases given and in similar ones. If, now, we give due consideration to the development of the densely branched organs of attachment which have been described above, it seems suggestive that copious and rapid branching occurs at just those places where the solvent action of some substance in the protoplasm is most evident. I may anticipate matters so far as to state that it is just at these parts that a ferment capable of swelling and dissolving cellulose is

- formed most abundantly, and it is in the highest degree probable that the presence of this ferment determines the place of origin of the branching.

I have tried to figure the process to my own mind somewhat 
as follows. The protoplasm, confined in a segment, goes on forming the ferment, until, there being no substance for the ferment to employ its energies on, the quantity of the latter becomes so great that it can no longer be retained, and the cellulose-wall undergoes softening at some point and is pressed forwards as a protuberance, a young branch. I imagine, moreover, that the continuous forward growth of the apex of any hypha takes place in a similar way, that is to say, the ferment-substance at the apex keeps the cellulose of the hypha at that place in a soft, extensible condition, and the pressure from behind stretches it and drives the tip forwards.

Next comes the second point, the direction in which the hypha or branch is constrained to grow. If we carefully examine cases such as those shown in Figs. 27 to 30 , it seems to me impossible to doubt that the hyphae exert an attractive influence upon one another, just as do the zoospores of certain algae, or as the contents of archegonia have been shown to attract spermatozoids, and the filaments of Spirogyra react on one another when conjugating ${ }^{1}$. A little reflection will show that, in principle, the cases I have here brought to light are by no means isolated ones. I may simply remind the reader that the oogonia of certain Phycomycetes not only attract the antheridial-branches ${ }^{2}$, but, if De Bary's supposition be correct, even determine their formation; then, again, the neighbouring sporidia of the Ustilagineae have long been known to conjugate in pairs, the connecting tubes taking the shortest course between the two sporidia ${ }^{3}$. Such junctions as I am describing are much more common than is generally supposed, and in all the cases known to me it is difficult to avoid the impression that the two (or more) bodies concerned are attracting one another in some way. When one sees a hypha deflected from its previous course through nearly a right angle as in Fig. 28, and $I$ have seen cases in another fungus where the deflection

v. Pfeffer, Unters. d. Bot. Inst. z. Tübingen, I. H. 3 .

3 Beitr. zur Morph. u. Phys. d. Pilze, IV.

3 See esp. Brefeld, Bot. Unters. ii. Hefenpilze, 1883; De Bary, Biol. of Fungi; also Marshall Ward, Phil. Trans., B, I887, Pl. 12. 
amounts to considerably more than a right angle, it seems to me impossible to avoid the impression that some attraction is exerted.

I have tried to account for the phenomenon of the directive action as due to heliotropism or geotropism, but entirely without success ; indeed, I never met with a fungus which seemed more indifferent to light than does this one, and the direction of the branches seems to have nothing to do with the direction of gravitation. There are two factors, however, which do seem to be of importance when considering the whole question of the direction of growth and the fusions of the hyphae; these are, firstly, the contact of hyphae with one another, or with a solid substance, and secondly, the direction in which the food-material lies with regard to free hyphae. Thus, as has already been pointed out, the contact of the young organs of attachment with the surface of the cover-slip stimulates them to exude ferment-substance and to branch, and the same is the case when they come in contact with the epidermis of a leaf or bud of a lily, with the difference that the exuded ferment there causes dissolution of the tissues, and the branching takes place in the dying mass of cells. In both cases, however, we have the irritation of contact first inducing accumulation of ferment at the spot, and branching follows. That one cause of the direction of growth of free branches is the presence of food-materials is suggested by the mode of development of such mycelia as the one in Figs. I5 and I6, where the successful growth is all into the drop of culturefluid, and similar directive influences are exerted by the tissues when once infected, as may be seen by the direct plunging in of the leading hyphae in Figs. 6 and 7, for plenty of evidence exists to show that these hyphae follow paths of least resistance prepared for them by a ferment in advance. Even in a culture liquid, and much more so in these cases, it may be a fair question whether the dissolved substances do not act as irritants keeping the ferment towards the tips of the hyphae, and if so there is no essential difference between the two cases so far. 
Although I believe that the branching is due to the localisation of ferment-substance in the hyphae or segment, and that the nutritive medium may have an influence in directing a growing branch when once formed, it seems quite clear that this gives no explanation whatever of the remarkable phenomenon of the attraction which leads to the junctions between the hyphae; and in the numerous cases, like those figured in Figs. 27-30, I cannot bring myself to believe that these factors alone determine the course and fusion of the hyphae. Moreover, I have convinced myself that mere contact between hyphae does not necessarily involve fusion, for in the case figured in Fig. 31 the upper hypha, having come accidentally in contact with the lower one, is seen to slide over in contact with the latter, without fusing with it at all, suggesting that one or both of the hyphae need to be in some special condition-I assume they must contain the ferment-substance in some necessary quantity or condition of action, or both-before they can conjugate. It is true that junctions are often established later in such cases as Fig. $3 \mathrm{I}$, at the point of contact where the two hyphae cross one another; but this only tends to prove the accuracy of the surmise that at the time of contact there was no attraction and no fusion, but that continued irritation at the point of accidental contact slowly causes a local accumulation of the ferment, and fusion eventually results at that point. It might be remarked that the case last quoted reminds one of the behaviour of some Myxamoebae prior to fusion into a plasmodium ${ }^{1}$, for in this instance also we are compelled to assume that some remarkable state is necessary before fusion can occur.

It remains to raise at least two more questions concerning this phenomenon In the first place, how is the attraction to be regarded? and in the second place, what object is served by the conjugation? To these questions I can give no definite

1 See Marshall Ward, An Aquatic Myxomycete, in Studies from the Biol, Lab. of the Owens College, vol. i, 1886, Pl. III and IV, pp. $64-85$. 
answer, and perhaps it is scarcely worth while to speculate further on so obscure a problem ; but it might be a fair subject for inquiry whether the action of the exuding ferment on the medium, i.e. food-materials in solution, is not to render the latter more directly available, and so mark out a track of least resistance as it were; at the same time it is not easy to see how this could happen in a liquid. It might also be asked whether the object served by the fusions is to nourish the whole mycelium more equably, or to equilibrate certain differences which have unavoidably made themselves apparent in the metabolic processes. In any case, the question at bottom seems to be a wide one, and possibly one affecting the particular case of reproduction in general. I do not suggest that this is a reproductive process as usually understood, but it seems probable that the stimuli concerned are fundamentally of the same nature.

We may now pass on to consider further cultures of the Botrytis, and the development of its conidia and conidiophores under conditions which could be controlled.

I have cultivated it as a saprophyte in the following media in addition to the normal Pasteur's solution, viz. in Pasteur's solution which had been partially exhausted by growing a crop of the fungus on it, and then filtered and sterilised; in Pasteur's solution to which various proportions of peptone were added; in cold water-extract of crushed bulbs of Lilium candidum; in cold water-extract of raisins ; and in certain other media which will be described subsequently, such as distilled water with bits of lily-bulb, fruit-juices neutralised with alkalies, and so forth.

In all these media the spores germinate, but the free development of the mycelium only continues when the liquid is acid, and the degree of acidity may be considerable. In a distinctly alkaline liquid no germination or growth whatever took place.

In all cases the course of development was the same in general, but with differences in detail. Confining attention for the present to the cultures in hanging drops, I found that 
in small drops of thin solutions, or in drops of partially exhausted Pasteur's solution, the mycelium produced fewer and poorer organs of attachment, and soon proceeded to the development of the conidiophores, and then ceased to grow further unless new food-materials were added; in denser and richer solutions, or in larger drops, on the contrary, the mycelium often grew from 10-12 days without passing to the development of the conidiophores. In the former cases it was possible to trace the whole development of the conidiophores and conidia without difficulty, because, there being few obscuring hyphae, etc., the same specimen could be kept under constant supervision.

In Fig. 32 I have drawn a mycelium cultivated from a single spore in a drop of partially exhausted Pasteur's solution: the culture was five days old. As seen, the mycelium is not very large or complex, and even the original spore can be recognised at $S$. On the hyphae at various places are large numbers of bubbles of gas, $A A$, a common occurrence when conidiophores are about to be produced: such bubbles are also found on the conidiophores themselves (Fig. 35) so long as they are submerged, but as they usually project from the surface of the drop of culture-liquid into the damp air of the chamber, the gas-bubbles are often not seen on them.

At $C C$ in Fig. $3^{2}$ are several conidiophores, bearing the well-known heads of Botrytis-spores which look like bunches of grapes. The conidiophores are produced in centrifugal order, by the outgrowth of thick blunt hyphae (Fig. 39) from certain not well defined branches of the mycelium.

The development is best illustrated by describing a concrete case-Fig. 34. The outgrowing colourless hypha is very full of dense protoplasm, often delicately vacuolated, and its rather blunt end soon begins to swell into a club-like shape: in this condition it looks very like the young sporophore of Mucor, only it soon becomes septate at short intervals. In the case figured this stage was reached by 4.45 p.m., and beneath the club-like end of the branch two little protuberances were appearing (Fig. 34, I). At 5 p.m. the protuberances had grown out into 
club-like arms, 2, and at 5.30 they, as well as the terminal swelling, were apparently studded with minute colourless spikules, 3 , which grew in length but did not increase in number. Fig. 34, 4, shows their condition at 5.45. Each of these spikules is a minute peg-like branch from the club, the protoplasm of both being continuous. At 6.5 p.m. (the same evening throughout) the little pegs or sterigmata were beginning to swell at their ends into minute, clear, bead-like bodies, 5 , which were well defined at 6.15, No. 6 , as young conidia, the rapid completion of which is most extraordinary -7 being drawn at 6.25 , and 8 at 6.40 p.m.

$\mathrm{Up}_{\mathrm{p}}$ to this stage the conidiophore may be still colourless, but after some hours of ripening, the sepia-hue shown in Fig. 9 makes its appearance. As already stated, these conidia fall from the sterigmata and germinate at once; they may even begin to germinate in some cases while still attached to the sterigmata.

It has sometimes happened that a young conidiophore becomes encrusted with minute crystalline particles (Fig. 36) which may be oxalate of lime: in my cultures, however, this has not occurred to any great extent except in those where raisin-extract was used.

One more feature needs description before we leave the conidiophores. In cases where the food-material is abundant, the conidiophore forms, as a rule, several successive heads of conidia in the following way. When the first head of conidia has been completed, a lateral branch springs from beneath the next septum lower down, as shown at $x$ in Fig. 33, and this branch elongates considerably, becomes septate, and in its turn forms a terminal head of spores (Fig. 37), and this process may be repeated several times ${ }^{1}$ (Fig. 38 ) : in a strong culture, in fact, I have had each of the branches in such a case as that of Fig. $3^{8}$ bear eight successive tufts of spores, one new one being developed every I 2-14 hours.

1 The resemblance of these forms to Corda's Gonatobotrys is obvious. The same process occurs in the conidiophores of Sclerotinia Fuckeliana. See De Bary, Biol. of Fungi, p. 48. 
It will be seen from the foregoing how very rapidly the conidia develop when once they begin to form. I have a few other observations on the rate of growth of the ordinary hyphae, but they are not sufficiently extensive or systematic to be of much value : they are added here simply to show how measurements might be made if the subject was pursued.

Thus, the young conidiophore in Fig. 39 was growing at the apex at such a rate that the portion $x-x^{\prime}$ in $a$ increased to $x-x^{\prime}$ in $b$, in the interval between I I. 30 a.m. and 3.20 p.m. (the temperature averaging $12^{\circ}-15^{\circ} \mathrm{C}$.), and two more septa were put in.

As another instance I may refer to Fig. 40, where the mycelium was growing in a culture-drop in which a piece of lily-bulb was suspended. At 2.55 p.m. a hypha was seen in the position shown in the drawing (Fig. $40 a$ ): $b$ shows the relative positions at $3.5 \mathrm{p} . \mathrm{m}$., and $c$ at $3.30 \mathrm{p} . \mathrm{m}$., the temperature averaging $\mathrm{I} 2^{\circ}-15^{\circ} \mathrm{C}$.

In Fig. 4I, the hypha $a$ was in the position drawn at 3.2 p.m., its apex pointing towards an intercellular space of a piece of lily-bulb near it. At 3.7 p.m. its tip was at the first $x$, and at 3.12 it was at the second $x$; the temperature was as before. As already stated, I regard these as mere notes taken by the way, since I was not at the time concerned with the question of the rate of growth, being in fact engaged in observing the entrance of the hyphae into pieces of tissue: so far as they go they are accurate, but numerous observations would be needed to make the matter clear in all its details, and it is not improbable that this fungus would afford a very favourable object for such observations.

I now pass on to the consideration of a phenomenon which seems to be of considerable importance, and so far as I can discover has never been described before.

In cultures of the fungus, both in hanging drops and on a larger scale, it is often noticed that the tips of the hyphae, at a certain stage of development, exude small drops of a translucent viscous fluid or semi-fluid substance, containing a number of minute brilliant granules; these drops may then 
enlarge and become distinctly granular, at the same time gradually acquiring a yellowish or slightly brownish hue (Figs. 43-45). I had occasionally seen a similar exudation of drops in previous cultures of fungi, and found among my drawings of cultures made in Ceylon in I 880 several similar cases; so far, however, I had not been able to establish any satisfactory explanation of the phenomenon, though the idea arose that the drops might be due to some substance manufactured in the cell in larger quantity than could be retained. Before offering a more definite explanation, I will describe the drops and their exudation in detail.

If the slightly swollen ends of vigorous hyphae of a well nourished mycelium be watched, it will be seen that sooner or later some of them become very full of particularly brilliant protoplasm (Fig. 45, I) : if such a hypha comes in contact with a solid body, such as the cover-slip, it simply begins to cling to it, and branches to form an organ of attachment as described on p. 327 . If it remains free, however, it gradually begins to exude a small translucent or nearly transparent viscid drop (Fig. 45, 2) from the tip, the protoplasm in the hypha becoming most beautifully vacuolated meanwhile. During the next few hours the exudation continues, and the vacuolation increases (Fig. 45, 3 and 4 ), and the drop slowly changes character as described-it becomes granular, and acquires a pale brownish-yellow hue. In some cases the segment of hypha becomes nearly emptied and collapses, and $I$ at one time suspected that the whole matter was merely a case of over-turgidity due to the absorption of water in quantity too great for the elasticity of the cellwalls. But it soon became evident that even if this were the case, there must be some cause at work determining the absorption of water at just that period in development. But when one reflects that these drops are extruded from vigorous hyphae developed in Pasteur's solution, or in the juices of fruits, etc., which can by no means be regarded as calculated to cause vacuolation by physical action, but, on the contrary, would act physically rather as plasmolysing agents, 
then it seems clear that we are here concerned with a process depending on changes in the metabolism of the plant-the hyphae, under the conditions given, extrude drops of substance from their tips. What is this substance?

On examining the margins of large mycelia (from one to four or five inches in diameter) grown on the surface of Pasteur's solution in properly sterilised flasks, I have found nearly every hypha extruding these drops (Fig. 44), and it was not difficult to obtain definite reactions. The drops react to Millon's test by giving a very evident and characteristic brick-red colour; nitric acid followed by ammonic hydrate results in the well-known golden yellow of the xantho-proteic reaction; Schulze's solution colours them yellow to yellow-brown, as also does iodine alone; alcohol coagulates them, and they stain with such dyes as would be expected to colour proteids.

All this, of course, would point to the drop consisting simply of the extruded protoplasm of the cell, and it will no doubt be asked why I regard it as anything else.

For the two following reasons, I look upon these drops as consisting in great part of a soluble ferment which has the property of swelling and dissolving cellulose cell-walls; I am not prepared to affirm that the drops in my cultures consist solely and entirely of the ferment, for it is far more probable that mucilage and proteids are mixed with it, and that the ferment only constitutes the brilliant colourless granules which become dissolved out from the extruded mixture of the drops. The two reasons upon which I lay such stress are, (I) I have succeeded in observing under the microscope the tips of the hyphae actually penetrate into and through the cellulose cell-walls of thin sections of lily-bulb placed in their path; and (2) a watery extract of the mass of hyphae referred to is found to swell up cellulose cell-walls when thin sections are placed in drops of it. Much of the rest of the present paper is concerned with the elucidation of these noteworthy phenomena.

But first, to make one or two further remarks concerning 
the 'ferment-drops,' as they may be termed. They occur in cultures growing in extract of raisins, etc., as well as in Pasteur's solution, and so far as I can determine, their formation depends not so much on the medium in which the fungus is growing as on the stage of development the plant has reached. So long as the mycelium is rapidly extending, i. e. developing numerous lateral branches, many of which are conjugating in the manner described on p. 329 , the extrusion of the drops is not observable. When a stage approaching maturity is reached, however, and rapid growth is ceasing, then the tips of free hyphae, and of the branches of organs of attachment, may be seen to extrude the drops

If a mycelium in this condition is placed upon the epidermis of a young lily-bud, the branches attack the tissues very actively, and destruction follows rapidly, and I may quote this as a further reason for believing that the drops contain the ferment. If to a mycelium in the condition above described, fresh food is offered, e.g. by adding a small drop of the culture-fluid, then active growth and branching etc. recommence, and the extrusion of the drops ceases meanwhile.

I think these facts point to the probability that so long as active growth and increase of surface of the fungus are going on, the ferment is not accumulated in undue quantities at any particular place, and no doubt the cross-connections established by the conjugating hyphae (p. 329) still further insure its distribution: as soon as this distributing process is brought nearly to a standstill, however, the ferment still being prepared by the protoplasm accumulates in quantities greater than can be retained, and breaks through the cellulose-walls in the manner described.

I may add that there is nothing absurd in supposing that ferment is still being formed after active growth has ceased, for such a preparation of ferment is regarded as taking place in the tubers, bulbs, etc. of higher plants during their periods of rest $^{1}$, and, further, the fact of the solution of the cell-walls 
in contact during the conjugation of the hyphae of the crossconnections may be cited as evidence that the ferment can dissolve its own cell-walls; moreover, the deliquescence of the walls of the organs of attachment (p. 328) points to the same conclusion, as also do known phenomena in other fungi.

We may now pass to the description of cultures and methods by which I succeeded in observing the actual piercing of the cell-walls by the tips of the hyphae of this fungus, and then to the subject of the action of aqueous extracts of the mycelium on cellulose, since these are the two important points to establish in proof of the above conclusions. Having found that when slices of the buds or leaves of the lily were placed in the culture-drop in which a spore was germinating, it was very difficult to avoid the introduction of foreign organisms, and that even when bacteria did not spoil the culture the products of disorganisation of the chlorophyllcorpuscles, etc. obscured the observation, it became necessary to adopt some modification of the process : this was successfully accomplished by the following means.

In the first place I employed glass-slips and covers which had been heated to near redness in a porcelain evaporating dish, and made the damp chambers of newly sterilised bibulous paper: then, taking care that none of the apparatus was touched with anything but recently heated forceps, needles, and freshly drawn glass capillary tubes, I placed a small drop of distilled water in the centre of the cover-slip ${ }^{1}$ by means of a freshly drawn capillary pipette, and sowed one spore in the drop. The single spore was obtained as follows. The conidiophores under a damp bell-jar usually have a tiny dew-drop at their ends, in which are numerous conidia, and it is not difficult to lift this off clean, with the point of a sterilised needle; the drop with its contained conidia is then placed in a larger drop of pure water, and the drop then fished with a clean needle. The needle lifts a small drop,

1 This is not so easy to do as it may seem, for the surface of the perfectly cleaned glass is often so readily wetted, that the drop is apt to spread as a film. 
which is placed on the cover-slip and examined with the microscope : if it only contains one spore, it is selected-if it contains more than one, the whole is rejected, and a new cover-slip and drop taken, and so on. Having obtained a satisfactory drop of water with one spore, I then placed in the drop also a thin section of either the ovary from a young lily-bud, or of the central scales of a lily-bulb, cut with a perfectly clean razor. Such sections may be cut quite clean and free from foreign spores, etc., if care is taken in removing the outer coverings, and I found that such sections of the bulb shaken up in freshly distilled water to remove some of the starch-grains could be kept. clean in the cultures for more than a week.

The most interesting results were obtained from such cultures. The pieces of bulb yielded to the water sufficient nutriment to start the germinating fungus-spore, and a normal mycelium was generally obtained on the third day.

In such cultures I have over and over again traced the hyphae growing across the field until their tips reach the piece of bulb, and observed that as growth proceeds the thin cellulose-walls of the bulb become swollen and evidently softened. I have also over and over again watched the tips of the hyphae enter into the substance of the cellulose-walls, and continue their growth in the plane of what would be the ' middle lamella' if such could be distinguished in these very thin walls. Moreover, such hyphae occasionally bore through from cell to cell, as shown in Figs. 57 and 58 , thus placing beyond all cavil the significance of these observations. To describe a concrete case :-In Fig. 58 the hypha was observed to gradually approach the edge of the section of lily-bulb, and to come vertically in contact with the cell-wall, figured at $a$, at 2.55 p.m. ; the onward growth of the hypha continued, pressing the tip against the surface of the wall and deflecting it slightly, as seen in $b, c$, and $d$. The progress of this mechanical effect was quite visible at intervals of two or three minutes, and in fact $b$ was drawn at $2.5^{8}$ p.m.; $c$ at 3.0 p.m.; and $d$ at 3.2 p.m., which of course implies that the changes 
were going on quite as rapidly as I could sketch them. On attaining the condition represented at $d$ (Fig. 5i), however, the effect of the irritation on the tip of the hypha began to make itself apparent; the tip slowly sank into the substance of the cell-wall ( $e$ was drawn at 3.7 p.m.), and appeared as if it was becoming continuous with its substance. This process went on for a quarter of an hour ( $f$ was drawn at 3.15 p.m.), until, at 3.24 p.m., the tip of the hypha, like a tiny bright globule, appeared, $g$, on the other side of the cell-wall : this rapidly enlarged, like a yeast-bud, and in four minutes presented the appearance shown in $h(3.28$ p.m.) and rapidly elongated to a continuation of the hypha ( $i$ was drawn at 3.30 p.m.). The hypha had pierced the cell-wall, slightly obliquely, by means of its tip. Now the tip of this hypha was just such an one as I found to extrude what I have called the 'ferment drops,' and it seems to me perfectly safe to assume that in this case the ferment at the tip was used to soften the cell-wall of the lily-bulb.

It should be remarked that in this case also the fungus is living as a saprophyte : the tissues of a section such as I have described are dead after a few hours at most of the treatment to which they have been subjected. I remind the reader of this, simply to show that it is not claimed for these observations that they demonstrate exactly what goes on when the fungus is living as a parasite. That they bear directly on that question is of course obvious enough. I need say no more about Fig. 57 than to observe that it illustrates a similar case of the rapid piercing of a cell-wall, the condition $b$ being attained ten minutes after $a$.

As already said, it is much oftener the case that when the tip of the hypha enters the cell-wall it runs in the plane of the middle lamella between the cells : I have not added figures of this, since what refers to Figs. 54-56 sufficiently illustrates the results of these cultures also.

It remains to state that the hyphae do not directly attack the starch-grains, nuclei, or other cell-contents, though they affect them indirectly: the starch-grains, for instance, are 
sometimes found to stain with methyl-violet after the action of the fungus on the tissues for two or three days.

I have in my possession, and can show, excellent permanent preparations of such cultures as have been described, and it may not be superfluous to describe briefly how such preparations may be put up.

Owing to the circumstances of the formation of the organs of attachment, it is always comparatively easy to secure any culture of more than three days old, and if the cover-slip with its hanging drop is lifted with forceps, and placed gently on the surface of a vessel of hardening reagent, on which it floats with the culture downwards, it usually happens that the mycelium, etc. is hardened with little or no disturbance. After many trials, with all kinds of stains, etc., I find that picronigrosin gives by far the most satisfactory results : after 24 hours the most delicate mycelia are beautifully fixed and stained, and the hardening may be then completed in absolute alcohol. After two or three changes, at intervals of a day, the alcohol has removed all the picric acid, but the specimen is stained steel-blue in various shades, and is so thoroughly hardened, that it may be passed through oil of cloves and xylol, and finally mounted in canada balsam, without collapse. When I state that I have thus mounted mycelia, showing the extruded 'ferment-drops' fixed and stained, it will readily be seen that the process is as satisfactory as it is delicate. I have also thus fixed and mounted cultures such as those described on p. 354, showing the hyphae in situ in the substance of the cell-walls (Figs. 55, 56).

If picric acid alone is used, the hardening may be accomplished similarly, and the preparations (after being washed with absolute alcohol) stained with carmine, methyl-violet, aniline blue, etc.; after careful and prolonged washing to remove every trace of acid, beautiful haematoxylin preparations may also be made. Such specimens may be so well prepared as to preserve the vacuolation in the hyphae: I have not been satisfied that nuclei exist in the hyphae. Some of the dyes bring out very clearly the zone of mucilage round the organs 
of attachment, and, as already stated, some of the methylviolet preparations of cultures with bulb-sections show the starch-grains deeply stained violet.

I have also obtained very beautiful results by thus hardening and staining whole buds of the lily in various stages of disease, and it may be remarked that this method of hardening and staining, especially with methyl-violet, affords a very easy test for the presence of fungus-hyphae or -spores on the epidermis of a leaf; and any one who is ignorant of the prevalence of fungi on leaves of all kinds during such a summer as the past one, may easily convince himself by laying the decolourised and hardened leaf in methyl-violet, and then examining the outside of the epidermis-the hyphae stand out sharp and clear on the colourless background. I have used this method with great success in infections, picking out spores and germinal hyphae with startling clearness: the method was also of the greatest use in preparing sections of the diseased tissues, such as those shown in Figs. 6, 7, 55, 56, etc.

Another very satisfactory method is to place the hardened and stained mycelium, attached to its cover-slip, in absolute alcohol which is floating on a layer of pure glycerine. In the course of a few days, the preparation with its cover-slip sinks into the glycerine, and may be removed and mounted in glycerine-jelly, the superabundant glycerine being gently washed off after the glycerine-jelly is thoroughly hardened. I also possess some very delicate preparations mounted in glycerine only.

In preparing some of these mycelia, and especially when placing pieces of large cultures - mycelia $3-4$ inches in diameter, and obtained in a manner to be described belowdirectly into absolute alcohol, it was usually noticeable that a white, apparently crystalline deposit fell to the bottom of the watch-glass or other vessel. I had the strongest reasons for believing that this precipitate carried down with it the ferment referred to so often, though I had not as yet obtained the precipitate in sufficient quantities to make positive statements concerning the white powder itself. Of this more will be said presently. 


\section{Marshall Ward.-On a lily-disease.}

I now pass to the consideration of the second of the two statements on p. 339 , viz. that aqueous extracts of the mycelium contain a ferment which swells and dissolves cellulose.

On reflection it seemed probable that if the 'ferment-drops' really contained the ferment, then, since the hyphae exuded the drops into the Pasteur's solution and other liquid media, one ought to be able to detect it there by its action on the tissues ${ }^{1}$; in other words, if the extruded drops contain a ferment which dissolves cellulose, then the liquid containing the ferment ought to have a solvent action on cellulose.

My first experiment met with decided success, so far as it went, for on placing thin sections of the bud of a lily in a few drops of the Pasteur's solution in which the fungus had been growing for several days, they underwent a distinct alteration in the cuirsc of the night, whereas similar sections in the same liquid, treated similarly except that it was boiled for two minutes, underwent no such change. The alteration consisted in a decided swelling and softening of the cellulose of the cell-walls, rendering their stratification remarkably distinct, and causing them to refract the light in a peculiar manner (see Figs. 59 and 60).

Since I could not be sure that such a solution was, so to speak, quite clean, or entirely devoid of other organisms, it became necessary to start a series of pure cultures on a larger scale to see if the phenomenon was a constant one.

After trying several methods, I finally adopted the following one as giving the best results on the whole. Flasks of about half a litre capacity were selected, washed, and heated on a sand-bath; when cool, they were carefully charged with about a quarter of a litre of the solution to be used-Pasteur's solution, with or without peptone, sterilised cold-water extracts of raisins, lily-bulb, etc.-and at once placed on a sand-bath, and the liquid boiled for 10-I 5 minutes; the neck was stopped

1 A ferment which causes the swelling and alteration of cellulose was found by De Bary in Peziza Sclerotionum (Bot. Zeit. 1886, Nos. 22-27), of which more shortly, and by Beyerinck in the Gumming of Trees under the influence of Coryneum Beyerinckii (Archives Neerlandaises, T. xix (1884), p. 43). 
with cotton-wool after five minutes' boiling, and while steam was rushing out. Next day the boiling was repeated for ten minutes; and after yet another twenty-four hours the boiling was again repeated, and so on. This well-known process of discontinuous sterilising gives excellent results.

In charging the flasks with spores I abandoned the method of soiving with the point of a heated needle, because it was not possible by this means to get any idea of the number of spores taken up, and still less of the purity of the sowing. The following modification of the ordinary process gave satisfactory results.

Perfectly clean sowings were made in drops of the sterilised culture-fluid on small cover-slips which had been heated until nearly red-hot, as if for culture in hanging drops; I need not give details as to the precautions taken, but of course the cover-slips were not touched after sterilisation except by heated forceps, needles, glass, etc. The sowings, as made, were examined under the microscope, the cover-slip resting on sterilised glass or metal rings, so that the drop hung from its lower surface. When I was satisfied by microscopic examination that the sowing was clean -i.e.contained only the Botrytis-conidia-the cover-slip was lifted by forceps at one corner, the cotton-wool plug removed for a moment from the neck of the flask, and the sowing and cover-slip dropped bodily into the culture-liquid in the flask; then the plug was replaced and pushed well in, and the flask labelled and placed on a shelf, where it remained perfectly still at a suitable temperature.

In the course of three days the tiny mycelia can be seen on the surface of the liquid in such flasks, and in less than a week it is usually possible to decide whether after all care a foreign spore has obtruded (as will happen occasionally) in the culture. In a fortnight the mycelia have coalesced, and cover the liquid as a grey sheet: further growth results in corrugation or folding of this sheet as it tries to extend in the confined space.

None of the hyphae dip far into the liquid, nor do the aërial hyphae project far from the surface; at the margins, 
organs of attachment are developed in contact with the glass, and conidia are formed on the surface of the sheet, but not in large numbers or in big heads, probably owing to the restricted access of free air.

With such cultures as these the following series of experiments were instituted.

\section{SERIES I.}

On July I7, three flasks were prepared and sterilised, corked with cotton wool, etc. as follows, and conidia of the Botrytis sown in them.

$\mathrm{r}=$ Pasteur's solution.

$2=$ Pasteur's solution, and a little peptone.

$3=$ Fresh urine.

On August I, dense myceiliai crusts had formed on Nos. I, 2, corrugated and growing out in all directions.

On No. 3, a mere film had commenced to form, and had then perished.

I then (August I) filtered ${ }^{1}$ the yellow liquid of No. I into two test-tubes, which had been properly sterilised : these tubes may be called $A$ and $B$ respectively.

I then boiled the liquor in $A$ for two minutes: that in $B$ was left untouched.

Damp chambers, properly sterilised, were then prepared as for cultures in hanging drops, and used as follows :-

$a=$ Two were arranged with the hanging drop of the boiled liquor (test tube $A$ ) and a thin section of lilybulb-scale placed in the drops.

$\beta=$ Two others were arranged exactly as above, but the drops consisted of the unboiled liquor (test-tube $B$ ).

$\gamma=$ Two were arranged as in $a$ (i. e. the drops consisted of boiled liquor), and two spores of the Botrytis placed in the drop as well as the lily-bulb-section.

$\hat{o}=$ Two others were arranged exactly as in $\gamma$, but with drops of the unboiled liquor.

\footnotetext{
1 Not without considerable difficulty.
} 
On August I, at 6 p.m., these damp-chambers were placed in a larger moist chamber in the laboratory, the temperature being $12^{\circ}-15^{\circ} \mathrm{C}$.

On Aug. 2, at ro a.m., I examined the above with the microscope.

The sections in $a$ and $\gamma$ were practically unaltered, but those in $\beta$ and $\delta$ presented a curious appearance, due to the peculiar brilliance of their cell-walls : the cellulose was somewhat swollen, and refracted the light so that the edges of the walls appeared coloured. It was evident that something in the liquid had caused a change in the cell-walls of such a kind that they became diffluent and swollen: moreover this something was destroyed by boiling.

I also devised the following parallel arrangements, as a sort of check on the foregoing.

On Aug. 1, eight culture-chambers were prepared as before, and the hanging drops constituted as follows :-

$\epsilon=$ Two of distilled water only.

$\zeta=$ Two of Pasteur's solution.

$\eta=$ Two of distilled water, with one or two Botrytisspores in.

$\theta=$ Two of Pasteur's solution with one or two Botrytisspores.

These eight cultures were placed in a similar dampchamber to the preceding eight, and at the same time; and they also were examined when the preceding ones were.

So far as the cell-walls were concerned, i.e. neglecting plasmolysis and other easily explained alterations, the sections in these cultures showed no change. The spores germinated normally.

I was by no means satisfied with these experiments; for although there was a distinct swelling of the cell-walls in the cases marked $\beta$ and $\delta$, it was not quite so conspicuous as in my rough experiment described on p. 346. However, repetition of the observations again led to the conclusion that the cell-walls did undergo the changes described. 
On Aug. 2, I took the remainder of the Pasteur's liquid from flask No. I, and employed it in three parts.

Part I was gently decanted into a clean test-tube: the nearly clear liquor contained a few spores and bits of mycelium.

Part II was filtered with difficulty into a second test-tube, yielding a clear yellowish liquor as in previous cases.

Part III was not only filtered, but also boiled for five minutes.

The tubes were stopped with cotton-wool, and marked $X, Y$, and $Z$ respectively, and in each tube $\mathrm{I}$ placed one or two short bits, with smooth clean-cut ends, of the bud, leaf, peduncle, and bulb of the white lily.

The tubes were then left until Io a.m. on Aug. 4-i.e. about 40 hours-in an ordinary temperature. The changes which had then ensued in the test-tubes $X$ and $Y$ were sufficiently obvious to be seen with the unaided eye, especially with the short cylindrical bits of peduncle.

Whereas those in the tube $Z$ (boiled liquor) still preserved their sharp smooth-cut ends and edges, those in $X$ and $Y$ (and especially in $X$ ) had their ends swollen and gelatinised, and projecting both longitudinally and laterally over the cut epidermis, so that the pieces looked like dumb-bells, the handle being formed of the intact epidermis and cuticle compressing the tissues beneath, and the heads of the swollen cells radiating at the ends.

Sections and microscopical examination showed that the tissues of the pieces in the test-tube $Z$ were practically unaltered; in $X$ and $Y$, however, the 'heads' of the dumb-bell-like pieces were composed of the separated swollen cells of the cortex and pith. Something in the liquor had in fact caused the dissolution of the middle lamella and the gelification of the cellulose. That this something is a ferment is not only highly probable from the preceding, but becomes almost a certainty from the ease with which it is destroyed on boiling the liquor. There were no bacteria to be observed in the fluid. 
Having repeated these experiments with like success, it seemed probable that better results, i. e. more intense action, might be got by employing an aqueous extract of the fungus: with this object the following series of experiments were made.

\section{SERIES II.}

On August 4, I removed with a newly drawn glass hook the mycelium from a flask-culture of three weeks' standing: the mycelium was about 4 inches in diameter, and about $3 \mathrm{~mm}$. thick, grey in colour, and of a tough almost cartilaginous texture. This mycelium was then crushed in a mortar in its own juice, i.e. with so much of the liquor as it had carried away from the flask, and a little distilled water. Owing to its slippery, semi-cartilaginous character, it was not easily pounded: after the operation the unpleasant-looking mess evolved a distinct sickly smell, not evident before crushing.

The whole mess was then poured into a clean flask, and the neck stopped with cotton-wool, and allowed to brew for an hour.

The liquor was then poured off and divided into two equal parts, as follows :-

Half was filtered ${ }^{1}$ into a small test-tube, labelled, and left intact.

The other half was filtered into a second tube, and boiled for five minutes.

The results were similar to those obtained previously; slices of lily-tissues placed in the unboiled liquor had their cellwalls swollen, whereas those in the boiled liquor underwent no such change. Again, however, I felt that the amount of swelling of the cell-walls was too slight to be absolutely convincing, so the following method was tried.

\footnotetext{
1 The process of filtering was difficult: for the first minute or so the liquor came through tairly rapidly, but it afterwards filtered throngh very slowly indeed. Thinking this might be due to some action on the filter-paper, I examined the latter subsequently; but I was unable to satisfy myself that the fibres were altered.
} 


\section{SERIES III.}

A fine mycelium, about the same size as the last, was removed on August 7 th from its flask (it had been growing since July 17 th on Pasteur's solution with a little peptone), allowed to drain, and pounded as before in a mortar, but with the addition of a few cubic centimetres of distilled water, instead of its own juice. The pounded mass was allowed to stand for an hour at the ordinary temperature, and then three sets of culture-chambers were arranged as in Series I.

In the first set of three chambers, the hanging drop was of the raw unfiltered extract.

In the second set, also of three chambers, the drop was of the unboiled but filtered liquor.

In the third set, also of three, the drop was of the boiled and filtered extract.

In each drop was placed a thin section of the peduncle of the white lily, and the preparations were examined from hour to hour.

In sets one and two the results were observable in the course of the first hour, and after six hours the cellulose-walls were all striated and swollen as in Fig. 60. It should be remarked that the swelling action was more vigorous in the unfiltered liquor than in the filtered one.

In the third set, where the drop consisted of the filtered liquor boiled for five minutes, no swelling of the cell-walls was observable in six hours.

I now felt satisfied that the action was really due to a soluble ferment, of the nature of a zymase, excreted by the fungus in question; but the question still remained as to the possibility of really isolating the ferment, for it had to be admitted that such an extract as the above must contain a mixture of substances.

Adopting the well-known method of precipitation by alcohol, the following experiments were carried out. 


\section{SERIES IV.}

A six-weeks' culture of the Botrytis, on Pasteur's solution with a little peptone, was removed from its flask, and the thick fungus-crust pounded in a mortar with a little distilled water : the mess was then allowed to digest for a few hours at $28^{\circ}-$ $30^{\circ} \mathrm{C}$. It was then filtered, the filtered liquor falling into a tall tube, and four or five times its bulk of alcohol was added. Contact with the alcohol at once caused a milkiness, which rapidly increased on agitation; and in less than a minute a series of flocculent white masses formed throughout the liquid, some of which slowly sank to the bottom, others floated quietly to the top. The tube was left to stand all night, at the ordinary temperature, and in the morning the white bulky flocks had increased a little, and numerous small tufts of a like nature were sticking to the sides of the tube.

I removed some of the floating flocculent masses, and examined them with the microscope: they consisted partly of amorphous substance reminding one of fibrine, and partly of crystalline substance of at least two kinds I thought at first that the crystals might possibly be those of tyrosin chiefly, with some leucine, but that idea was not supported by their examination by a chemical friend. Be this as it may (and it is of secondary importance because the crystals etc. only act as a vehicle), the partly amorphous, partly crystalline flocks, after being dried at the ordinary temperature over sulphuric acid in the partially exhausted receiver of an air-pump, formed a greyish mass, which swelled and partly dissolved in distilled water.

I placed some of it in a small watch-glass, with a little distilled water, and allowed it to digest two hours; I then added a few sections of the pedicel of Lilizm auratum (being unable to obtain Lilium candidum), and allowed them to soak for eight hours at $30^{\circ} \mathrm{C}$. The results were as before-the middle lamellae of all the parenchyma cells were destroyed, and the cells isolated as if they had been boiled, while the cellulose- 
walls swelled up, and became distinctly lamellated and folded as in Fig. 60.

Similar sections, lying for an equal time in the boiled solution, gave no such reactions, nor did sections lying in water.

It seems clear, then. that the precipitated flocks carried with them a substance which dissolves in water and produces the changes in cellulose which have been described; and I think it will not be denied that this substance is the ferment so often referred to. As yet, however, I cannot claim to have isolated the ferment in a state of absolute purity, though it seems probable that this will yet be accomplished. It seems extremely probable that the ferment is of the same nature as the one extracted by De Bary from carrots which were destroyed by the mycelium of Peziza Sclerotionum.

Having now obtained a fairly complete history of the Botrytis as a saprophyte, we will proceed to describe its behaviour as a parasitic fungus. As will have been seen from the previous part of the paper, I was led to attempt infections on account of the peculiar behaviour of the small spots on the leaves and buds, etc.

During July and August conidia were several times sown in drops of distilled water, on the surface of young lily-buds, or of leaves, obtained from non-infected plants at a distance as well as from specimens nearer the infected area.

The conidia germinated readily on the epidermis, and in from 20 to 48 hours the germ-tubes were usually found in the solid cellulose-substance of the cell-walls of the epidermis. Looked at from above, as in Figs. 46 and 47 , it was by no means obvious at first that the germ-hyphae had penetrated the cuticle; but closer observation showed that the tips of the longer or shorter germ-hyphae attached themselves to the surface of the cuticle, and then dissolved their way in, discolouring and destroying the cell-walls and cuticle in the immediate neighbourhood. In no case did I see the end of a germhypha enter a stoma, though it is by no means denied as. improbable that such an entrance may occur. It was often 
possible to assure myself that the protoplasm of the conidium passed into the germ-hypha in the cell-wall, and the hypha branched and grew in the plane of the surface of the bud, leaf, etc. Moreover, transverse sections through the recent infections show beyond all doubt the presence of the hyphae in the substance of the cell-wall, as seen in Figs. 55 and 56 : these preparations also show clearly that the cellulose in which the hyphae are running is swollen considerably, and it seems impossible to reject the explanation that this is due to the action of the ferment secreted by the fungus, and isolated by precipitation, as described, and that the change here is of the same nature as the swelling of the cellulose in the experiments referred to on pp. 348-353.

Among other variations of the conditions of infection, I tried the effect of sowing the conidia in drops of Pasteur's solution on the epidermis of the buds and leaves. The phenomena of infection were not markedly different, the chief noteworthy point being that the germ-hyphae gave rise to branches outside as well as inside the cuticle. These outside hyphae then repeatedly branch, and form organs of attachment which rapidly destroy the cuticle beneath, and enter the tissues: such a case is illustrated in Fig. 50, the specimen being observed from within. This exceptional mode of infection is peculiarly interesting, because it resembles one described by De Bary $^{1}$ as the only mode occurring with the mycelium derived from ascospores of Sclerotinia (Peziza) Sclerotionum, where the mycelium is incapable of becoming parasitic unless it has previously been nourished as a saprophyte. Here, again, as will be shown later, the entrance of the hyphae into the tissues depends upon the excretion of a ferment which dissolves cellulose. I shall, however, return to this point subsequently.

But perhaps the best and most convincing preparation showing the causal relation between the fungus and the spots was the one figured in Fig. 53. I had several times found that

Bot. Zeit. 1886, Nos. 22-27. 
a mycelium exists in the dead cell-walls of the red or brown spots, such as that of Fig. 2, and among numerous sections I found the one drawn (Fig. 53). In order to make out more details it was allowed to swell slowly in very dilute ammoniasolution, and the spore then came into view, its germ-hypha having entered beneath the cuticle, and grown and branched in, and at the expense of the gelatinised cell-walls, which were in a collapsed state when the section was cut.

Such preparations as this and those in Figs. 51 and 52 leave little doubt that what takes place in infection is as follows. The Botrytis-conidium germinates on the damp epidermis, and the tip of the germ-hypha excretes sufficient of the ferment to soften and dissolve the cell-wall, which it then penetrates. Feeding on the substance of the dissolved and swollen cellulose, the hyphae grow and branch more and more, and excrete larger and larger quantities of ferment. The cells thus attacked lose water, and the protoplasm dies and turns brown, and finally the whole may collapse, and leave simply a shrivelled mass of brown dead cells, in the dried-up walls of which the young mycelium is trapped, and may persist in a dormant condition. In this way are produced the discoloured sunken spots so characteristic of the disease in a certain stage.

If there is sufficient water present to ensure that the swollen cell-walls do not dry up, then the hyphae branch and grow in the cellulose as shown in Figs. 55 and $5^{6}$, and soon gain sufficient energy to put forth numerous branches downwards and in all directions, destroying the subjacent tissues with extraordinary rapidity (as in Figs. 6 and 7). That the mycelium in the small, brown, sunken spots is only in a dormant condition can be shown by keeping these under a damp bell-jar ; it is only because the cell-walls have dried up too rapidly that the mycelium lies in a dormant condition, because the ferment cannot diffuse and prepare the path of destruction necessary for the rapid progress of the hyphae, the growth of which is of course also dependent on the presence of water.

I may now consider the very difficult and involved question 
of the nomenclature and systematic position of this fungus. It will have been noted that it has been referred to in this paper throughout, so far, simply as a Botrytis, and it should be added that $I$ have used this term in a broad sense : it may now be useful to see if this sense can be narrowed.

The genus Botrytis was first introduced by Micheli, but gradually became so split up and altered, that its original signification was practically lost. It used to include the group Peronosporeae, until Corda separated Peronospora, and De Bary showed that the so-called Botrytis infestans of the potato-disease must not only be separated as one of the Peronosporeae, but must be placed in a distinct genus among these, and he re-named it Phytophthora infestans. The old genus Botrytis also contained a number of other forms which have since been separated under various names. Thus Link removed Haplaria, a form common on waterplants; and he divided many of the remaining forms.into Botrytis proper and Polyactis. Allied to these, and variously arranged with them among the so-called Mucedines, were the forms Gonatobotrys, Botryosporium, etc. ${ }^{1}$

All such arrangements were based almost entirely on the description and figure of observers who took the forms as they occurred at the moment of observation, paying little or no regard to the possible changes they might undergo in the course of their life-histories. The classical case of Peronospora (Phytophthora) infestans may be quoted as showing the results to be obtained by patient and careful study of the details of development. When De Bary and others had elucidated the biology of the potato-disease fungus, it was seen

1 See Berkeley's Cryptogamic Botany, and Cooke's Handbook. Polyactis is again united with Botrytis (as a sub-genus) by Saccardo in his 'Sylloge' (vol. iv. p. 1 16), the group thus containing about 100 'species.' The genus Botrytis is defined by him as follows :- 'Botrytis, Mich. em. Link.-Hyphae steriles repentes; fertiles vage dendroideo-ramosae, erectae. Ramuli modo tenues apice acutiusculi (Eubotrytis), modo crassiores obtusiusculi (Polyactis), modo apice inflato-verruculosi (Phymatotrichum), modo apice cristulati (Cristularia). Conidia prope apicem ramulorum varie congregatae nec vere capitata, continua, globosa, ellipsoidea $v$. oblonga, hyalina v. laete colorata.' 
that its only claim to alliance with its supposed congeners lay in a superficial resemblance during one phase of its lifehistory. Now, apart from other instances, it has resulted from the studies of Tulasne (who first demonstrated that Botrytis (Polyactis) cinerea is the gonidial form of a Discomycete), Brefeld, De Bary, and others of the school of mycologists who have striven to found species and genera only on a knowledge of the entire life-history of the forms, that the group of forms known as Polyactis among English authors, but still called Botrytis by the Germans, are really only stages-gonidial or conidial forms-in the life-history of certain Pezizas ${ }^{1}$.

The question now arises, to which, if any, of these groups is the fungus of this lily-disease to be relegated. It is not a question to be answered off-hand, in face of the warnings to be gathered from a consideration of the many mistakes which have arisen from authors founding species on incomplete information; nor do the descriptions of authors help us much, though good figures exist in some cases and are of great service in the process.

But there is other evidence to hand, which has to be discussed, for the disease in question, together with its fungus, has been already noticed in England, and in part described. On referring to the 'Gardeners' Chronicle,' for $1881^{2}$, there is a short article on the subject by the Rev. M. J. Berkeley, beginning with remarks on a letter from Mr. Wolley Dod. In this letter we are informed that various species of Lilizm, and especially $L$. auratum, after a fortnight or so of wet, stormy weather, had become spotted - ' Rust-coloured patches come upon the leaves of buds as if they had been burnt; if the buds are not completely destroyed, the flowers become imperfect and distorted, and the whole plant has a blighted appearance.' All kinds of lilies were attacked in the beds in

\footnotetext{
1 Thus, as has so often occurred with Fungi, different phases in the life-history of one and the same form have received special names. Cf. De Bary, Biol. of Fungi, p. 238.

${ }^{2}$ P. 340.
} 
the open, but specimens in pots under the shelter of greenhouses escaped. Berkeley, who seems to have been already acquainted with this disease, points out that it is due to the ravages of a fungus presumably allied to Peronospora, although he had never seen it produce zoospores.

Berkeley named this fungus Ovularia elliptica ${ }^{1}$, and says the spores are 'elliptic, resembling in shape and size those of many of the larger Pezizas.' As we shall see, there was probably something approaching the prophetic in this intuitive remark. The disease received no further notice, so far as I can discover, until the past summer. In the 'Gardeners' Chronicle' for August I8th, I888, Mr. W. G. Smith gives a good outline figure of the conidiophores and conidia of this fungus, and-on evidence of the slenderest possible naturealters the name of the fungus to Peronospora elliptica. I feel no difficulty in concluding that the fungus is the same in all . cases, though of course it is barely possible, or rather conceivable, that two different forms have been mixed up. However, Mr. Smith's drawing suggests that the fungus is a 'Polyactis,' and the suggestion receives support if we turn to his own capital figure of Polyactis vnlgaris (Botrytis vnlgaris) in the 'Gardeners' Chronicle' for Febuary, $1886^{3}$, where this fungus is described as following other fungi on and in diseased Cucurbitaceae.

Now it so happens that this Polyactis vulgaris has been very abundant on the vegetable marrows in my garden this year (in August and September), and I have taken considerable pains to cultivate it from the conidia in the pure condition. I have also cultivated with equal ease and care a similar, if not identical form of Polyactis on Phaseolus, also in my own garden.

These cultures have shown that the conidia, sown in Pasteur's solution, rapidly give rise to a mycelium of branched, septate hyphae, which form cross-connections, organs of attachment, and in short behave almost exactly as the conidia and mycelium of the fungus of the lily-disease. I cannot

1 'Floccis hic illic nodosis, sporis magnis ellipticis laevibus.'

\footnotetext{
2. p. 184 . 
yet positively assert that the Polyactis on Phaseolus is the same as that on the marrow, but the differences, if they exist, are so slight as to escape detection.

But although Polyactis vulgaris behaves so far almost exactly like the lily-fungus, there are one or two points of difference to be noted, of sufficient importance to prevent any one from confounding them; to make myself quite certain of this, I made simultaneous sowings of the three forms-that on the lily, that on Phaseolus, and that on the vegetable marrow-in drops of the same brew of Pasteur's solution, and all treated exactly alike.

In the first place, the conidia of the lily-fungus are about twice as large as those of the Polyactis ${ }^{1}$ on beans and marrows ;

1 It is neither necessary nor useful to give a full list, but the following data are of importance in the discussion which follows :-

Polyactis vulgaris, Fr., has conidia measuring 10-1 $2 \times 7-9 \mu$, according to Saccardo. If we take the measurements of different observers, however, the conidia must vary considerably, from ro-1 $6 \times 7-10 \mu$.

Polyactis cana, Berk, has spores measuring $30-33 \times 15^{-18} \mu$, as $\mathrm{I}$ learn from Mr. Massee, who has kindly examined the specimens in Berkeley's Herbarium at Kew for me.

Polyactis cinerea, Pers. (Botrytis cinerea of the continental writers), has conidia measuring 8-9 $6-7 \mu$, according to Saccardo.

Polyactis fascicularis, Corda. The conidia measure $12-15 \times 6-8 \mu$.

Now these are the chief British forms in Cooke's Handbook (187 I, vol. ii. p. 6oI), Polyactis vera being a rare form of which I have no measurements.

Mr. Massee has been so good as to send me drawings and measurements of the following additional forms: I have also to thank Mr. G. Murray for measurements of several species :-

Polyactis capitata, Berkeley's Herb., a white form with conidia measuring 20-25 $\times 12-16 \mu$.

Polyactis umbellata, DC., a dark rusty-brown form with rounded conidia measuring I $^{-17} \boldsymbol{\mu}$.

And a very interesting form Botrytis (Cristatella) corolligenium, Cke. and Mass., found at Kew on decaying Calceolaria-flowers. The plant is pure white, and the type in the Kew Herbarium has ovoid conidia measuring $25 \times 15-18 \mu$.

It is sufficiently clear from the above that the lily-Botrytis, with conidia measuring about $25 \mu$ long $\times 15 \mu$ broad, cannot be confounded with the forms $P$. vulgaris or $P$. cinerea, or any of the small-spored forms. Nor can I identify it with Berkeley's $P$. cana, though his $P$. capitata (conidia $20-25 \times 12-16$ ) seems to present some not unimportant features of resemblance. This could only be decided by comparing fresh specimens and by cultivation. In any caşe, it seems clear that, if there is anything at all in the measurements, we must look for this 'species' among the large-spored forms. 
secondly, the spores of the latter germ inate more rapidly, and at once-much more quickly than those of lily-fungusproceed to the development of large organs of attachment of the complex tassel-shape, like those in Fig. 26.

Some time ago I received from Kew a piece of moribund stem of an Amorphophallis, covered with a grey mould which turned out to be a Botrytis (Polyactis), very like P. vulgaris, if not identical with it: in the interior of the stem were numerous small black sclerotia, each about the size of a piece of mouse-dung, and exactly resembling it to the unaided eye. These sclerotia arose from the same mycelium as the Botrytis, and cultures of the conidia of the latter gave rise to mycelia, etc., exactly similar to those just described for Polyactis vulgaris. I mention this because it affords another indication of the kind of fungi we are here concerned with, and furnishes another confirmation, if one is needed, of the connection between Botrytis (Polyactis) and the sclerotium-bearing Pezizas.

But there is abundance of evidence in addition to show that the fungus of the lily-disease is a Botrytis, of the Polyactis group, from which I may select the following.

In ${ }^{1877-78}$ Eidam $^{1}$ published some interesting results. He cultivated the spores of Botrytis elegans, Lk., in nutritive solutions such as extract of plums, and obtained sclerotia developed from the mycelium.

In 1880 Frank $^{2}$ published an interesting account of a fungus parasitic on turnips, the mycelium of which developed both sclerotia and Botrytis-conidia : the sclerotia produced a Peziza which Frank calls $P$. sclerotioides, Lib., but, as De Bary ${ }^{3}$ points out, this is a slip for $P$. Sclerotionum, Lib. Frank also calls his Botrytis, $B$. cinerea, a name which De Bary rejects, because B. cinerea is the Botrytis-form of Peziza Fuckeliana. $B \bar{e}$ this as it may, Frank found that the conidia of his Botrytis, when sown in the turnip-plant, put forth germ-hyphae

1 Ber. d. Schles. Gesellsch. 1878 , p. 151 . Bot. Zeit., 1878 , p. 174 .

2 Die Krankheiten der Pflanzen, p. 530.

3 Bot. Zeit., I 886 , p. 457 . 
which directly infected it, and produced a mycelium which developed sclerotia, and again Botrytis.

In 1886 Sorauer ${ }^{1}$ published the result of his investigations on a disease of onions, caused by a Peziza. Here, again, he found that a Botrytis was developed as well as a sclerotium, and that infections could be made with the Botrytisspores.

That Botrytis cinerea is only a conidial form of the sclerotium-bearing Peziza Fuckeliana has long been established, as already said, and an excellent account of this fungus is to be found in De Bary's book ${ }^{2}$.

In 1886 De Bary published a remarkable paper ${ }^{3}$ on 'Some Sclerotiniae and Sclerotium-diseases,' in which the attempt is made to clear up much of the obscurity which hangs around this group of Pezizas. In this paper De Bary gives in detail the results of his study of Peziza Sclerotionum, Libert ${ }^{4}$. $\mathrm{He}$ assumes a knowledge of the structure and development of the black sclerotia and the long-stalked funnel or trumpetlike hymenophores (the Peziza-form), giving some facts of importance for their identity ${ }^{5}$. The trumpet-like form is especially characteristic of the clay-coloured cups. The spores are discharged by ejaculation from the asci, and may thus be obtained very clean and in any quantity. Each spore is ellipsoid, measuring on the average about $11-12 \mu$ long by $4.5^{-6} \mu$ broad. De Bary expressly states that no gonidiaform of this fungus is known, and all his cultures were from the ascospores.

The ascospore germinates at once in culture solutions,

1 Handb. der Pflanzenkrankheiten, ii. p. 294.

2 Comp. Morph. and Biol. of Fungi, etc., I 887, Engl. ed., especially pp. 2 I9, 224 , 380.

3 Bot. Zeit., 1886, Nos. 22-27.

- Sclerotinia Libertiana, Fuckel. This Peziza is named Hymenoscypha Sclerotiorum, Lib. in Phillip's British Discomycetes, 1887 , and has received many other names.

5 The best general account of the sclerotium is in De Bary's Morph. and Biol. of Fungi, pp. 218,219 , etc., and in Brefeld's Schimmelpilze, iv. p. 112 ; also Pirotta, N. Giorn. Bot. Ital. xiii. p. I 30 . Other references are given in the first-mentioned book. 
developing a mycelium of branched, septate hyphae, which form cross-connections, and develop organs of attachment so like those already referred to that no one can doubt their being organs of the same kind: they are of the tasselform so rare in the lily-fungus, however, and more like those formed by the Botrytis on Phaseolus and vegetable marrow, than those of the lily-fungus. After forming numerous organs of attachment, the Peziza-mycelium, if well nourished, proceeds to develop sclerotia on the surface, and in centrifugal order.

De Bary then goes on to show that his Peziza can be cultivated with ease as a saprophyte on many kinds of pabulum-wine-must, juices of fruits, and artificial solutions, - and that its ordinary mode of life is saprophytic; but that under certain conditions it becomes a parasite, and the most remarkable point in his paper is the demonstration of how this facultative parasitism comes about.

As a parasite, it may attack (I) reservoirs of reservematerials, especially carrots and turnips; (2) the seedlings of various dicotyledons; and (3) the vegetative parts of older dicotyledonous plants. He expressly states that in spite of all attempts he could not cultivate it, or find it parasitic on living monocotyledons.

It was particularly easy to cultivate the Peziza on carrots and turnips, the mycelium forming dense masses on the surface and in the tissues, softening them as if they had been boiled, and ending in the development of sclerotia. In the stems of living plants, the mycelium affects especially the pith and cortex, also softening the tissues, and forming sclerotia. The hyphae grow especially between the cells, destroying the middle lamella and causing the cellulose-walls to gelatinise as if boiled.

But although the mycelium of Sclerotinia (Peziza) Sclerotionum can thus behave as a parasite, De Bary obtained the astonishing result that the germ-hyphae from the ascospores cannot directly penetrate into the living plant, and that this inability to enter living tissues persists until the young mycelium has been invigorated by nutrition as a saprophyte. In other

B b 2 


\section{${ }_{364}$ Marshall Ward.-On a lily-disease.}

words, the germ-hyphae from the ascospores of this Peziza are unable to pierce the living tissues, but when they have been nourished in a saprophytic manner by absorbing food-materials derived from dead organic sources, the mycelium at length obtains the power of piercing the plant and killing it.

De Bary gives several striking proofs of this, the simplest being that when the ascospores were sown on the cut surfaces of two carrots, one of which had been killed by boiling, the other still living, the germinal tubes at once entered the dead carrot and formed mycelia, sclerotia, etc., whereas they were unable to enter the living carrot at all.

The seedlings of Petznia violacea were found to be very sensitive to the fungus, but if ascospores were brought into a drop of water with the living seedling, the germ-tubes failed to enter the tissues of the Petunia for days : if both were placed in a drop of culture-solution (instead of pure water), however, the germ-hyphae of the Peziza rapidly grew to mycelia which at once entered and destroyed the tissues of the Petunia-seedlings.

Numerous other experiments led to the conclusion that Sclerotinia (Peziza) Sclerotionum is a saprophytic fungus, the mycelium of which can become parasitic, however, if previously invigorated by being nourished as a saprophyte.

It is neither possible nor necessary to devote attention to all the interesting morphological points about this fungus, and the reader is referred to De Bary's paper for many details passed over here.

De Bary then goes on to show that when the mycelium has been nourished up to the necessary degree as a saprophyte, it develops the organs of attachment already referred to; these organs on coming in contact with the tissues of a plant, kill the subjacent epidermis, etc., and, flourishing at the expense of the products of solution of the poisoned tissues, gather more strength, and send down branched hyphae in all directions.

The action of these hyphae on the tissues is worth noticing. The cells in their neighbourhood are found to lose water, 
and collapse, the protoplasm shrinking and turning brown ; and these destructive processes extend in advance of the hyphae.

From all the facts De Bary concluded that the organs of attachment excrete a substance which poisons the cells; the latter then collapse, and their expressed sap then serves as food for the mycelium, which thereupon sends branches further into the tissues, the whole process becoming more and more active pari passu.

Having concluded that a diffusible substance is excreted by the fungus, De Bary then examined the juices expressed from his rotted carrots; and he found that pieces of the internodes of the bean, or of fresh carrot, or of seedlings of Brassica, if put into this juice, underwent strongly marked destruction in a few hours. This destruction consisted in plasmolysis of the cells ; followed by a slight swelling of the cellulose-walls, and finally the dissolution of the middle lamellae.

To make a long story short, De Bary found that the expressed sap of the carrot, after destruction by the Peziza, contained a substance or substances which swell cell-walls and kill the tissues. From various experiments, and from the fact that the sap loses these properties on being boiled, it is concluded that the sap contains one or more ferments or enzymes, which cause the changes in question. This was still more clearly proved by using the fluid expressed from the sclerotia : this fluid was strongly active in dissolving the cellwalls.

Then follow experiments on a large scale to prove that the infection takes place from plant to plant by means of creeping mycelia, which produce organs of attachment on contact with the epidermis, and these act in the way described.

De Bary then points out that this Peziza attacks kidneybeans, Petunias, Zinnias, sunflowers, and some other Compositæ, carrots, turnips, and occasionally potatoes.

The parasitism is very remarkable; while one of two species closely allied will resist attack, plants of very distant alliances will suffer. Moreover there are some curious cases of local and individual predisposition to attack, which are discussed. 
On the whole, seedling-plants suffer most, and De Bary comes to the conclusion that it is the amount of water in the cells and cell-walls which probably determines whether the plant resists or succumbs to the attack of the fungus : this, again, possibly depends on the conditions of the cellulose. As already stated, he found it impossible to infect monocotyledons.

I have quoted the substance of this paper at some length, because it seems to me to throw considerable light on the nature of the lily-fungus ${ }^{1}$.

It is clear that in the development of septa, cross-connections, and organs of attachment, the mycelium developed from the conidia of the lily-Botrytis presents some remarkable analogies with the mycelium developed from the ascospores of Sclerotinia (Peziza) Sclerotiorum. In its saprophytic habit, moreover, and the ease with which it can be grown on very different media, the lily-Botrytis resembles the Peziza: in its parasitism it is more pronounced, but even here it presents some resemblances worth noting, especially in its mode of destroying the tissues of the host, by means of a soluble ferment. Here, however, the resemblances cease. De Bary expressly points out that his fungus has no gonidial stage; it could not be cultivated on monocotyledons; and it is prone to the rapid development of sclerotia. The mode of infections is quite different, and the lily-Botrytis easily forms gonidia in cultures.

Nevertheless, I am driven to conclude that, although I have never yet succeeded in growing sclerotia or peziza-cups from the Botrytis, it is either a stage in the life-history of a Pezisa of some kind, or at least its alliance lies in this direction; and, in support of this opinion, I would again insist upon the facts, already quoted, that Botrytis cinerea is known to be a gonidial form of Peziza Fuckeliana; and several other forms of Botrytis are stages in the life-history of sclerotium-bearing Pezizas, though De Bary does not seem to allow the latter statement. There are many species, good and bad, of these Pezizas, and it

1 As I write, Dr. C. von Tubeuf, of Munich, sends me an account of a Botrytis parasitic on Abies Donglasii; the conidia measure $9 \mu$ by $6 \mu$ (Beitr. zur Kenntniss d. Baumkrankheiten, 1888, p. 4). 
is only necessary to take up any systematic work on the group $^{1}$ to see what confusion prevails as to their nomenclature and classification. De Bary has shown that Peziza Sclerotion $m$ has probably received a different name for almost every species of host-plant on which it has been found, and it is in the highest degree probable that various species, good and bad, now pass under different names in England and on the Continent.

In conclusion, then, the lily-Botrytis is probably a gonidial stage in the life-history of some Peziza; whether the alternative form is developed on some other plant, or whether it is lost, cannot be said. It is quite conceivable, however, that in consequence of their pronounced parasitism this fungus and Phytophthora infestans may have lost their alternative form.

The attempt may now be made to give a general account of the disease, and to see how far we can explain the epidemic nature of this year's attack, from what is known so far.

It is quite certain, at the outset, that the fungus itself was present in the lily-beds in my garden in I 886 and I 887 : why then did it remain sporadic during those years, and become epidemic in 1888 ? I think the explanation is to be sought along the following lines.

The parasitism of the fungus depends, as we have seen, in the first place on its power to excrete a ferment which softens cell-walls, and enables the hyphae to feed on their substance: this ferment acts best in a slightly acid medium, and it requires water, if for no other purpose, to enable the ferment to diffuse, but also because the more watery the cellulose the more easily it is dissolved.

Now if we compare the meteorological records for 1887 and I $888^{2}$, especially for June, July, and August, the period of active development of the flower-axes of the lilies, it will be found that, in the district referred to, the summer of 1887 was particularly hot and dry, and the lilies that year produced

1 E.g. Phillips' monograph (British Discomycetes) in the International Scientific Series ( 1887 ), which, by-the-bye, contains no reference to Botrytis or gonidial forms that I can discover. $\quad 2$ See Table and remarks in Appendix on page 370. 
magnificent flowers. The sunshine was intense, and the general temperature high; this means rapid transpiration and energetic assimilation, processes by which hard, thick cellulose-walls are produced. The cuticle is also well developed, thick, clean, and continuous under such conditions; and growth is steady, there being no superabundance of water, the light being bright.

During the corresponding period of the past summer, however, the conditions were very different. The weather was for weeks very wet, and cold, and dull ; this means a lowering of the rate of transpiration, and an increase of water in the plant ; assimilation is also less energetic, and thin, watery, ill-developed cellulose-walls are one result. I had abundant opportunities of convincing myself that the young lily-buds were gorged with water for hours at a time, and, in fact, many of them showed irregular protuberances of tissue due to the disturbances of growth consequent on this. In this dull, wet weather, moreover, respiration was going on more rapidly (in proportion to assimiliation) than is normally the case, and an increase, however slight, of the acids in the tissues may very well have resulted from this. Although the temperature was low, the turgid condition of the buds would be one cause of the thin and imperfect cuticle that often existed, and it seems not improbable that in the continued wet weather, small quantities of food-materials and acids in solution would diffuse to the outside. I made several attempts to determine this, but was unable to satisfy myself further than that the damp cuticle gave an acid reaction.

But even if the liquid bathing the cuticle contained no food-materials, the other conditions were obviously in favour of the fungus, and I have no doubt the epidemic nature of the disease this year depended, not so much on any changed properties of the fungus, as in alterations in the tissues of the host. Of course, once started, the fungus found another advantage in being able to develop such enormous quantities of conidia in the damp atmosphere, and these would be blown about in millions by the wind.

Accepting De Bary's results with Peziza Sclerotionzm, I 
regard his fungus as a form physiologically midway between the ordinary saprophytic Pezizas, and my parasitic one; in other words, De Bary's fungus is in process of being educated to parasitic habits. It might be supposed at some future time to gradually produce a little more ferment in its ripening spores, or a stronger form of the ferment ; if it did so it would be able to penetrate the plant at once, as does the lily-fungus, without previous invigoration by dead nutritive materials. This is, of course, a hypothesis; but I venture to point out that it is in accordance with some of our recent knowledge, and that, if clearly kept balanced in the mind as a suggestive hypothesis, it would be well worth while to work through the group of sclerotium-forming Pezizas, to see if they are not a series of fungi in the transition state of saprophytes which are gradually becoming parasites. There are some facts, indeed, which render it not improbable that this hypothesis might be extended to other groups of Pezizas, but the above is sufficient for the present. At a future time I hope to have something to say on the possible bearing of this on an old suggestion of my own as to the gradual loss of sexual organs in these fungi; for these sclerotium-bearing forms are gradually losing the last traces of them.

\section{APPENDIX.}

I add the following summary of the average meteorological record for the months of June, July, and August of 1886,1887 , and $\mathrm{I} 888$, which $\mathrm{I}$ owe to the kindness of my colleague, Prof. McLeod, F.R.S., who has for many years tabulated the results obtained from observations at the Royal Indian Engineering College, Cooper's Hill, and which observations are communicated to the Meteorological Office every month. It is to be deplored that the Cooper's Hill Station is not provided with continuous recording instruments, and that we have no register of the amount of sunshine; nevertheless much information can be gained from the tables, from which extracts are appended. 


\begin{tabular}{|c|c|c|c|c|c|c|c|c|c|c|}
\hline & \multirow{2}{*}{$\begin{array}{l}\text { Barometer. } \\
\text { (Inches.) }\end{array}$} & \multicolumn{2}{|c|}{ Thermometer. } & \multirow{2}{*}{ Dew Point. } & \multirow{2}{*}{$\mid$\begin{tabular}{c|} 
Pressure \\
of Vapour. \\
(Inches.)
\end{tabular}} & \multicolumn{2}{|c|}{ Temperature. } & \multirow{2}{*}{$\begin{array}{c}\text { Solar } \\
\text { Radiation. } \\
\text { Maximum. }\end{array}$} & \multirow{2}{*}{$\begin{array}{l}\text { Terrestrial } \\
\text { Radiation. } \\
\text { Minimum. }\end{array}$} & \multirow{2}{*}{$\begin{array}{c}\text { Rain. } \\
\text { (Inches.) }\end{array}$} \\
\hline & & Dry Bulb. & Wet Balb. & & & Maximum. & Minimum & & & \\
\hline \multirow{2}{*}{$\begin{array}{l}\text { I886 } \\
\text { June }\end{array}$} & 30.0052 & 56.953 & $52 \cdot 477$ & $4^{8 \cdot 417}$ & $-343^{2}$ & $\left(74^{\prime} I\right)$ & $(38 \cdot 5)$ & $\left(139^{\circ} 1\right)$ & $(29 \circ)$ & $(\cdot 618)$ \\
\hline & $29^{\circ} 9771$ & 62417 & $5^{6 \cdot 607}$ & $5^{1 \cdot 73^{\circ}}$ & 3910 & $64: 43^{6}$ & 48.527 & I $22 \cdot 377$ & $4 I^{\prime} 333$ & $1 \cdot 382$ \\
\hline \multirow{2}{*}{$\begin{array}{l}1887 \\
\text { June }\end{array}$} & $\begin{array}{c}30 \cdot 2134 \\
(30 \cdot 477-\end{array}$ & $\begin{array}{r}60.173 \\
-20.654)\end{array}$ & $55^{8} 896$ & $52 \cdot 307$ & 3954 & $(8 \mathbf{1} \cdot 2)$ & $(43 \cdot 3)$ & $\left(134^{-8}\right)$ & $(30.5)$ & $(\cdot 639)$ \\
\hline & $3^{\circ}=1834$ & 67.513 & 59.520 & $53 \cdot 3^{8} 7$ & 4120 & $69 \cdot 283$ & 50.047 & $116 \cdot 397$ & $4 I^{\circ} 973$ & $I \cdot 289$ \\
\hline \multirow{2}{*}{$\begin{array}{l}1888 \\
\text { June }\end{array}$} & 29.9508 & $57^{2} 27^{\circ}$ & 53.827 & 50.743 & 3774 & $\left(83^{\circ} \cdot 0\right)$ & $\left(44^{\prime} 4\right)$ & $(133 \cdot 8)$ & $\left(30^{\circ} 4\right)$ & $(\cdot 519)$ \\
\hline & $29^{9} 9^{2} 5^{6}$ & $\begin{array}{r}-29500) \\
62 \cdot 623\end{array}$ & $5^{6.803}$ & $5^{2 \cdot 043}$ & 3966 & $64 \cdot 687$ & 49.557 & $113 \cdot 837$ & $43 \cdot 6 \circ 7$ & $2 \cdot 350$ \\
\hline \multirow{2}{*}{$\begin{array}{r}\text { r886 } \\
\text { July }\end{array}$} & $\begin{array}{l}29 \cdot 94^{26} \\
\left(30^{\circ} 337\right.\end{array}$ & $\begin{array}{r}62 \cdot 597 \\
-29 \cdot 456)\end{array}$ & $5^{8 \cdot 25^{2}}$ & $54 \cdot 619$ & 4312 & $(82 \cdot 8)$ & $(45.3)$ & $(140 \cdot 8)$ & $\left(35^{\circ} \mathrm{I}\right)$ & $(\cdot 318)$ \\
\hline & 29.9178 & 67.823 & $60 \cdot 345$ & $5454^{2}$ & 4346 & 70.281 & $53 \cdot 445$ & $\mathrm{I} 26 \cdot 368$ & $4^{6 \cdot 100}$ & $1 \cdot 842$ \\
\hline \multirow{2}{*}{$\begin{array}{l}1887 \\
\text { July }\end{array}$} & $\begin{array}{l}30 \cdot 0642 \\
(30 \cdot 374-\end{array}$ & $\begin{array}{r}66 \cdot 055 \\
-29 \cdot 669)\end{array}$ & $59 \cdot 86_{5}$ & $54^{9} 94^{8}$ & $\cdot 4368$ & $(86 \cdot 3)$ & $\left(44^{\circ}\right)$ & $(139 \cdot 7)$ & $(31 \cdot 6)$ & $(\cdot 255)$ \\
\hline & 30.0287 & 73.035 & 63.013 & $55 \cdot 607$ & $\cdot 44^{63}$ & $75^{\circ} \mathrm{O}_{4} 2$ & $54^{\circ} 04^{8}$ & $127 \cdot 303$ & $44 \cdot 177$ & $.8 \mathrm{r} 3$ \\
\hline \multirow{2}{*}{$\begin{array}{l}\text { I888 } \\
\text { July }\end{array}$} & 2977898 & $57 \cdot 561$ & $54 \div 55$ & $5^{1} \cdot 84^{8}$ & $\cdot 39^{12}$ & $(68 \cdot 9)$ & $(4 \mathrm{I} \cdot 7)$ & $\left(129^{\circ} 4\right)$ & $\left(3^{6} \cdot 2\right)$ & $(1 \cdot 062)$ \\
\hline & $29^{\circ} 7825$ & 60.842 & $5^{6.223}$ & $53 \cdot 194$ & $\cdot 4089$ & 63719 & $51 \cdot 306$ & 111168 & $47 \cdot 44^{2}$ & $5 \cdot 954$ \\
\hline \multirow{2}{*}{$\begin{array}{l}\text { I886 } \\
\text { Aug. }\end{array}$} & $\begin{array}{c}30^{\prime} 010_{5} \\
\left(30^{\circ} 286-\right.\end{array}$ & $\begin{array}{r}6 \mathrm{r} \cdot 106 \\
-29 \cdot 689)\end{array}$ & $5^{8 \cdot} 55$ & $55^{\cdot 626}$ & $44^{69}$ & $(85 \cdot 8)$ & $\left(4 I^{\prime} 3\right)$ & $(137 \cdot 8)$ & $\left(34^{\circ} I\right)$ & $(157)$ \\
\hline & 29.9801 & 68.607 & $62 \cdot 257$ & $57 \cdot 318$ & 4797 & $695^{6} 4$ & $53^{\cdot 245}$ & 125.822 & $4^{6} \cdot 187$ & 615 \\
\hline \multirow{2}{*}{$\begin{array}{l}\text { I887 } \\
\text { Aug. }\end{array}$} & $30 \cdot 0078$ & $\begin{array}{r}6 r \cdot 593 \\
-2 \times 680)\end{array}$ & $5^{6 \cdot 590}$ & $5^{2} \cdot 377$ & $39^{67}$ & $\left(860^{\circ}\right)$ & $(44 \cdot 3)$ & $(136 \cdot 9)$ & $(28 \cdot 6)$ & $(\cdot 890)$ \\
\hline & $29^{\circ} 97^{28}$ & 69.626 & $60 \cdot 070$ & $5^{2} \cdot 830$ & $\cdot 4058$ & $72 \cdot 100$ & $5^{2 \cdot 235}$ & $123 \cdot 277$ & $4^{2} \cdot 065$ & $1 \cdot 765$ \\
\hline \multirow{2}{*}{$\begin{array}{l}\text { I888 } \\
\text { Aug. }\end{array}$} & $\begin{array}{c}30 \cdot 0272 \\
(30.279\end{array}$ & $\begin{array}{r}5^{8} \cdot 966 \\
-29 \cdot 629)\end{array}$ & $5^{6 \cdot 010}$ & 53.393 & 4154 & $(8 \mathrm{r} \cdot 8)$ & $\left(4^{2 \cdot 6}\right)$ & $(136.9)$ & $(32 \cdot 3)$ & $(\cdot 983)$ \\
\hline & 30.0085 & $\begin{array}{r}63573 \\
\end{array}$ & $58 \cdot 300$ & 54.003 & $\cdot 4232$ & 65.806 & $5^{\circ} 95^{2}$ & 114.003 & $44^{\circ} 745$ & $2 \cdot 411$ \\
\hline
\end{tabular}


If now we examine this table, it will be seen that it bears out generally the truth of my personal observations on the weather of the months named in I 888 , as compared with 1887 and 1886.

In the first place the barometric pressure was lower in June and July of I 888 than in the same months of I 886 and I887, though this is not quite the case in August.

On looking at the wet and dry-bulb thermometer, we notice that in 1888 the readings of the dry-bulb were low in June, and markedly so in July and August, as compared with the corresponding months in $1886-7$. As regards the wet-bulb, the same fact comes out-the readings are low. The dew-point is also relatively low; but whereas the dew-point throughout shows considerable similarity, the differences of temperature as indicated by the dry-bulb are, as said, very great.

The temperature columns are again instructive, especially as contrasted with 1887 , both minima and maxima being distinctly low, for July and August especially. The same with solar radiation, a rough measure of the quantity of heat and light derived from the sun, not only are the maxima lower in I 888 , but the averages are markedly so.

I have also made out some further details from the daily tables. In June 1888 the maximum temperature was below $60^{\circ} \mathrm{F}$. on seven days, whereas in 1887 this only occurred twice, and in 1886 five times. In July 1888 it was below $60^{\circ} \mathrm{F}$. on five days, on none in 1887 , and on one only in I886. In August this was the case on four days in 1888 , but never the case in 1887 or 1886 .

When we come to the rain-fall, the generalisation is strikingly illustrated, especially in July. Moreover, I have satisfied myself that this holds in detail, taking day by day. In June 1886 , for instance, there were 14 days on which rain fell (including four days when the rainfall was less than 009 in., and one day on which more than 0.5 in. fell). In the same month in 1887 , rain fell on eight days (including four days with less than 009 in., and one with more than 0.5 in.); and in 1888 there were twenty-two rainy days in June (including 
six with a fall of less than .00 in., and one when it exceeded $0.5 \mathrm{in}$.

Taking the month of July. In 1886 rain fell on fourteen days (including four with less than $.009 \mathrm{in}$., and none with so much as 0.5 in.). In 1887 there were eleven days on which rain fell (including two days when the fall was less than .009 in.- on none did it reach 0.5 in.). Whereas in July, I 888, we had twenty-eight rainy days (only three of which registered so little as .009 in., while on five of them the fall exceeded $0.5 \mathrm{in}$.),

Then again in August, there were twenty-four days in 1886 when rain was registered (but sixteen of these yielded less than .009 in., and none so much as 0.5 in.). In 1887 there were twelve rainy days (including four with less than .009 in., and one with more than 0.5 in.). But in August, 1888, we had twenty-two rainy days (and only seven of these showed so little as 0.009 in., while on two days more than $0.5 \mathrm{in}$. fell). It has not seemed worth while for the present purpose to give further details than those above, but I may say that the daily register quite bears out these results.

It is a well-known fact that the estimation of the relative amounts of sunshine and cloud, blue sky, haze, etc., is a very difficult matter; nevertheless some indication of the state of affairs seems to be obtained by comparing the details for the months and years given.

I have made out that in June of 1886,1887 , and 1888 , respectively, the total amount of cloud observed (two observations daily) was as follows, 600 being the possible maximum-i.e. if the sky had been completely overcast at every observation, the amount would have been registered as 600 .

In June 1886 the amount of cloud $=45^{\circ}$, and there were twenty-seven days on which blue sky was registered as seen during some part of the day.

In June 1887 the cloud $=376$, blue sky being registered for twenty-three out of the thirty days.

In June 1888 the number recording cloud rose to 578 , and blue sky was registered for sixteen days only out of the thirty. 


\section{Marshall Ward.-On a lily-disease.}

Taking the register for July, we find 448 of cloud (out of a possible 620 ) in 1886 , and blue sky was seen on twenty-eight of the thirty-one days.

In $\mathrm{I} 887=375$ of cloud, and blue sky was seen on thirty days out of the possible thirty-one.

In I 888 the cloud amounts to 557 , and only eighteen days are recorded as showing any blue sky.

If we then look at August. In 1886, the total cloud registered $=4 \mathrm{I} 3$ out of 620 , and blue sky was visible on twentynine of the thirty-one days.

In 1887 the cloud $=399$, and blue sky was seen on twentyeight days.

In 1888 the cloud $=499$, and twenty-five days out of the thirty-one showed some blue sky.

Of course these are rough estimates, but so far as they go they entirely support the impression I had formed independently-viz. that the summer of I 888 has been dull, wet and cold, compared with 1887 especially.

\section{SUMMARY.}

In the foregoing memoir, I have attempted to bring out the whole life-history of the fungus causing the disease described, so far as it occurs on the living and dying lilies. Commencing with the description of the external symptoms, disease-spots, etc., I then show that the fungus always found in their tissues is a Botrytis (of the form now called Polyactis). The spores, cultivated in suitable media, give rise, after germinating in a characteristic manner, to a copiously branched and septate mycelium, with well-marked and easily-recognised morphological features, and which presents some physiological phenomena of much interest and importance.

Some of its branches form cross-connections by a process so like conjugation, that it is difficult to avoid applying that term to it; their conjugation is preceded by an attraction for one

- another, which is shown by mutual deflections of the growing 
hyphae. Certain of the free branches develop into the curious 'organs of attachment,' which glue themselves to solid bodies in much the same way as the tendrils of Ampelopsis, and develop in response to a similar irritability to contact. These organs, as well as the tips of other hyphae, secrete relatively large quantities of a ferment, and I have shown that in culture-media this cellulose-dissolving ferment may accumulate to such an extent that the hyphae can no longer contain it, and it causes dissolution of the cellulose at the tips of the hyphae, and consequent extrusion of the protoplasm and ferment in the form of drops. The details of accumulation of the ferment, so far as they could be traced by the microscope, are given, as also some interesting reactions, methods of staining, preparation, etc.

The development of the Botrytis-heads, or sporophores, and conidia, is given in detail, as well as some observations on the rate of growth of the hyphae. Then follow some observations of considerable interest on the passage of the hyphae in and through the cellulose cell-walls of the lily. By means of special cultures it was found possible to observe, step by step, the actual piercing of the cellulose by the tip of the fungus-hypha, and its further growth in the walls; it results from these observations that the tip of the hypha in contact with the cellulose, probably in consequence of the irritation of contact, excretes relatively large quantities of ferment-substance and dissolves its way into the cell-wall, swelling up the cellulose and feeding upon the products of solution, and causing destruction of the tissues by isolating the different cells as if they had been boiled.

I have also obtained from large pure cultures of the fungus in sterilised flasks, solutions which produce the same swelling and dissolution of the cellulose as those met with in chambercultures, containing sections of the peduncle, leaf, ovary, etc. of the lily, and their cell-walls and middle lamellae undergo solution in a few hours when placed in these aqueous extracts of the fungus. Since the swelling etc. does not occur if the extract is previously boiled for from two to five minutes, the 
evidence is all but conclusive that the changes are due to the ferment referred to. Considerable success was obtained towards obtaining the ferment pure, by precipitation from the extracts with alcohol. In conclusion of this part of the paper I describe the phenomena of infection, and the details of the parasitism of the fungus, discussing the reasons for the disease being at one time sporadic, and at another epidemic, in its attacks.

The second part of the paper is occupied with the question of nomenclature, and the systematic position of the fungus, and I have given what seem to me very strong reasons for concluding that the fungus is a so-called Botrytis of the Polyactis-type-a gonidial form of some sclerotium-bearing Peziza. Further, that while it is certainly distinct from Polyactis vulgaris, Botrytis cinerea, and other accepted forms, it may or may not be the gonidial form of a Peziza which has been already described. This can only be decided when the sclerotia and peziza-cups are found. Its mycelium presents several resemblances in its physiology to that of Sclerotinia (Peziza) Sclerotiorum, but such important differences occur in other respects that it must be unhesitatingly kept separate. In this part of the paper the literature is given so far as it applies, and guidance to the complete literature of the whole subject indicated. In conclusion some remarks of a hypothetical nature are offered, suggesting that the Pezizas of the Sclerotinia-group and their allies are in a transition state from saprophytes to parasites, and that the form now studied is one which has succeeded in becoming a true parasite. 


\section{Marshall Ward.-On a lily-disease.}

\section{EXPLANATION OF FIGURES IN PLATES XX, XXI, XXII, XXIII, AND XXIV.}

Illustrating Professor Marshall Ward's paper on a lily-disease.

\section{PLATE XX.}

Fig. I. The upper portion of a flowering raceme of Lilium candidum, with the buds and bracts attacked by the Botrytis; the ashen-grey colour on the buds is due to tufts of the conidiophores of the fungus. Natural size, drawn July 7 th.

Fig. 2. A bud with one 'disease-spot' in an early stage of development; the depressed centre of the spot is orange-brown, the margin paler, and a zone of green surrounds the whole. Nat. size.

Fig. 3. The above spot in a later stage of development : the powdery appearance is due to the spores. Nat. size.

Fig. 4. One of the above buds completely destroyed by the fungus; the tissues are permeated in all directions by the close-set mycelium, and the whole is reduced to what practically resembles a sclerotium. Nat. size.

Fig. 5. Portion of a thin section through a lily-bud in the condition of the lower ones of Fig. I. The tissues of the bud are unrecognisable, as they are practically replaced by fungus-hyphae, forming a dense, tongh felt-work of the nature of a stroma or sclerotium. Two tufts of conidiophores are seen, projecting from the surface. Zeiss B.

Fig. 6. Portion of thin section across such a spot as that in Fig. 3, at the margin where the healthy and moribund tissues join. The dead and dying cells in and near the region attacked by the fungus, collapse and cause the whole to shrink. In the swollen cell-walls are the hyphae, cut across in all directions: these are already sending conidiophores to the exterior, and long hyphae down between the killed cells of the interior. Note the collapsed lumina and swollen walls of the latter. Zeiss B.

Fig. 7. Portion of the last preparation more highly magnified, and showing more clearly the cut hyphae running in the substance of the cell-walls of the epidermis and other tissues. It also shows the base of young conidiophores, and the long, thin, almost vertical hyphae sent down between the cells of the interior. Zeiss $D$.

Fig. 8. Portion of a transverse section through a sepal of the lily near a diseasespot, but at a place just beyond the region actually occupied by the hyphae: the cell-walls are becoming swollen, discoloured, and disorganised, and the contents of the cells destroyed.

Fig. 9. Group of conidiophores in various stages of development, growing into the damp air from the surface of the bud. A hypha $(a)$ is protruded, and then $(b)$ becomes septate, and puts forth a few branches; these branches swell at their ends (c), and develop minute peg-like protuberances at various points. Each of these pegs gives rise to a conidium, by swelling at its distal end into an oval body, which soon acquires the typical characters of a spore (e). Zeiss D.

Fig. 10. Young hypha emerging through the epidermis of the petal of a lily. The development is very rapid, as will be seen later. Zeis $\mathrm{D} / 2$.

Fig. 1 1. Conidia, and their germination. To the left are two recently detached 


\section{Marshall Ward.-On a lily-disease.}

conidia in water; the larger one measured $\frac{2}{x^{0}} \mathrm{~mm}$. long by $\frac{1}{60} \mathrm{~mm}$. broad. At $\alpha$ is a conidium germinating after lying three hours in water at the ordinary temperature; $a^{\prime}$ the same four and a-half hours later; $a^{\prime \prime}$ the same fifteen hours later still. Zeiss D.

Fig. I2. A similar culture in water. The conidium $\beta$ was placed in water at I I.30 a.m. on July 7 th ; at 2.30 p.m. it had germinated as shown. $\beta^{\prime}$ the same at 7 p.m.; $\beta^{\prime \prime}$ the same at ro a.m. next-day (July 8$) ; \beta^{\prime \prime \prime}$ the same at 7 p.m. on July 8th. It will be noticed that as the process of germination advanced, the protoplasm in the spore became very frothy, and finally passed entirely into the hyphae (e.g. $\beta^{\prime \prime}$ and $\beta^{\prime \prime \prime}$ ). Still later $\left(\beta^{\prime \prime \prime}\right)$, the protoplasm in the hyphae also became vacuolated. On the $9^{\text {th }}$ of July all growth had ceased, the culture remaining as shown in $\beta^{\prime \prime \prime}$, except that the vacuolation had increased: and by July I Ith (i.e. after nearly five days in water) the septate hyphae contained little ut water and a few granules. The tip of the long hypha had swollen a little. All Zeiss $D$.

Fig. 13. A conidium germinating in water, in which a slice of a lily-bud had been placed; the influence of the food-material was at once evident from the outset in the more numerous and stronger branches, etc. The spore was sown on August I st, at 4 p.m., and the drawing made August 2nd, I I a.m. Zeiss D.

Fig. I 4. Germination in Pasteur's solution. The spore $a$ was sown on July 7, at 7 p.m., and when drawn (10 a.m., July 8th), had been germinating for 15 hours. Zeiss D.

\section{PLATE XXI.}

Fig. I5. The same conidium nine hours subsequently, the culture going on in a hanging drop of Pasteur's solution. Zeiss $\mathrm{D}$.

Fig. I6. The same culture on July $9^{\text {th }}$ at 8.30 a.m., i. e. $13 \frac{1}{2}$ hours subsequently. The drawing was made as exact as possible, but under a lower power (Zeiss B), in order to get the whole in. It will be noticed that at three places, marked $x$, cross-connections have been established between the hypbae.

Fig. I7. The same culture 48 hours later still, i. e. after four days from germination. A few of the ends of main hyphae have been omitted, but otherwise the courses of the branches are shown as correctly as possible: numerous crossconnections are observable, and certain small groups of tendril-like thin hyphae should be noted. The spore is still to be seen to the left below. Zeiss $B$.

Fig. I 8 . Two of the tufted groups of thin tendril-like hyphae of the above, more highly magnified. Zeiss $D$.

Fig. 19. A portion of the above mycclium, showing the cross-connections established by the fusion or conjugation of neighbouring hyphae. Note the remarkable case near $x$, where two short branches from below have curved over, and fused with one from above; while two other short branches, curving over still more towards the same point, have failed to establish the connection. Zeiss D.

Fig, 20. Portions of the mycelium of Fig. I 1, showing the characteristic outlines of the tendril-like endings of the branches: the two slightly swollen ends, $x \times$, are beginning to stick to the glass. Only the ontlines are drawn, but the whole of the branches were full of bright protoplasm, and rapidly growing. Zeiss D.

Fig. 2I. One of the curious swollen endings of hyphae in various stages of growth. The mycelium was three days old, and growing in Pasteur's solution. $a$ was the condition at 2.30 p.m.; $b=3.30$ p.m. ; $c=6.3 \circ$ p.m., and $d=10.30$ p.m. 


\section{Marshall Ward.-On a lily-disease.}

It is these swollen, club-shaped endings which form the 'organs of attachment.' Zeiss D.

Fig. 22. One of the organs of attachment seen from above, as it adheres to the cover-slip from which the culture-drop was hanging. Its cell-walls deliquesce, and glue themselves flat on to the glass, as shown in profile in Fig. 23. Such an organ often puts forth a branch at $\times$ (Fig. 23), and goes on growing thence. Zeiss J.

Fig. 24. Three of the organs of attachment viewed from above, through the glass as before, showing how they may branch, and go on growing. Zeiss E.

Fig. 25. Young organs of attachment branching to form the tufts shown in Fig. $\mathrm{I}_{5} e$. Zeiss D.

Fig. 26. Medium-sized (by no means the largest) tassel-like organs of attachment produced by the repeated branching of smaller ones. Zeiss D.

\section{PLATE XXII.}

Fig. 27. The end of a hypha from the same mycelium as Fig. $15 . \quad a$ represents the condition of affairs at 7 p.m. on July $18 ; b=6.30$ a.m. on the I9th; $c=10$ a.m. (I9th); $d=11.40$ a.m.; $e$ was drawn at $12.30 ; f$ at $12.45 ; g$ at 12.55 ; and $h$ at I.IO p.m. The chief point of interest is the gradual outgrowth of the branch, $x$ (in $d$ ), and its fusion with another one. The branch $\times$ appeared as a slight protuberance about I I.30 a.m., and in ro minutes presented the condition figured in $d$; at 12 o'clock the small branch opposite to it appeared, and was as shown in $e$ at I 2.3O. It is noteworthy that the direction of the upper branch $\times$ changed, and it curved so as to point the apex towards the new protuberance. As the two apices approached, the growth became more rapid, and at $12.55(\mathrm{~g})$ the tips were nearly in contact. Absolute contact took place at 1.3 , as nearly as I could determine; at r.10 the protoplasm of the two branches was continuous, as in $h$. The system was watched up to the evening, but no further changes of importance were noticed. Zeiss D.

Fig. 28. Another case where the ends of two hyphae, at first growing at an angle, gradually turn so as to grow in the same straight line and fuse. $a$ was drawn at 10 a.m., $b$ at 10.45 , and $c$ at I 2.30. As before, the protoplasm eventually became continuous by the fusion of the apices. Zeiss $D$.

Fig. 29. Another case of the same kind, but less accurately timed. $A$ was the condition of affairs at 4 p.m., and $B$ was drawn at 8 p.m.; but it should be noted that the junction was already complete, at the point marked $x$. Zeiss $D$.

Fig. 30. At I 2.45 a junction was already established where the two hyphae cross at $X$ (in $a$ ), and just below two branches are growing out towards one another; to the right is a long, thin, straight hypha shooting across from another branch; at 2.25 the end of this straight hypha was in contact with one of the first-named branches $(0$ in $\beta$ ), and soon after it effected a junction. The effect of this was apparently to stop the further development of the two short branches near $o$; and they did not join. The mycelium from which this preparation was taken was cultivated in thick raisin-extract. Zeiss D.

Fig. 3I. Taken from same mycelium as last. $a$ was drawn at 4 p.m., and $b$ at 4.10 p.m. The tip of the upper branch slid slowly along the lower branch, but no junction was established between them. In some cases junction is established eventually at the point of crossing after $24-4^{8}$ hours. Such cases seem to prove that the hyphae must be in some special condition before they can establish junctions, Zeiss D. 


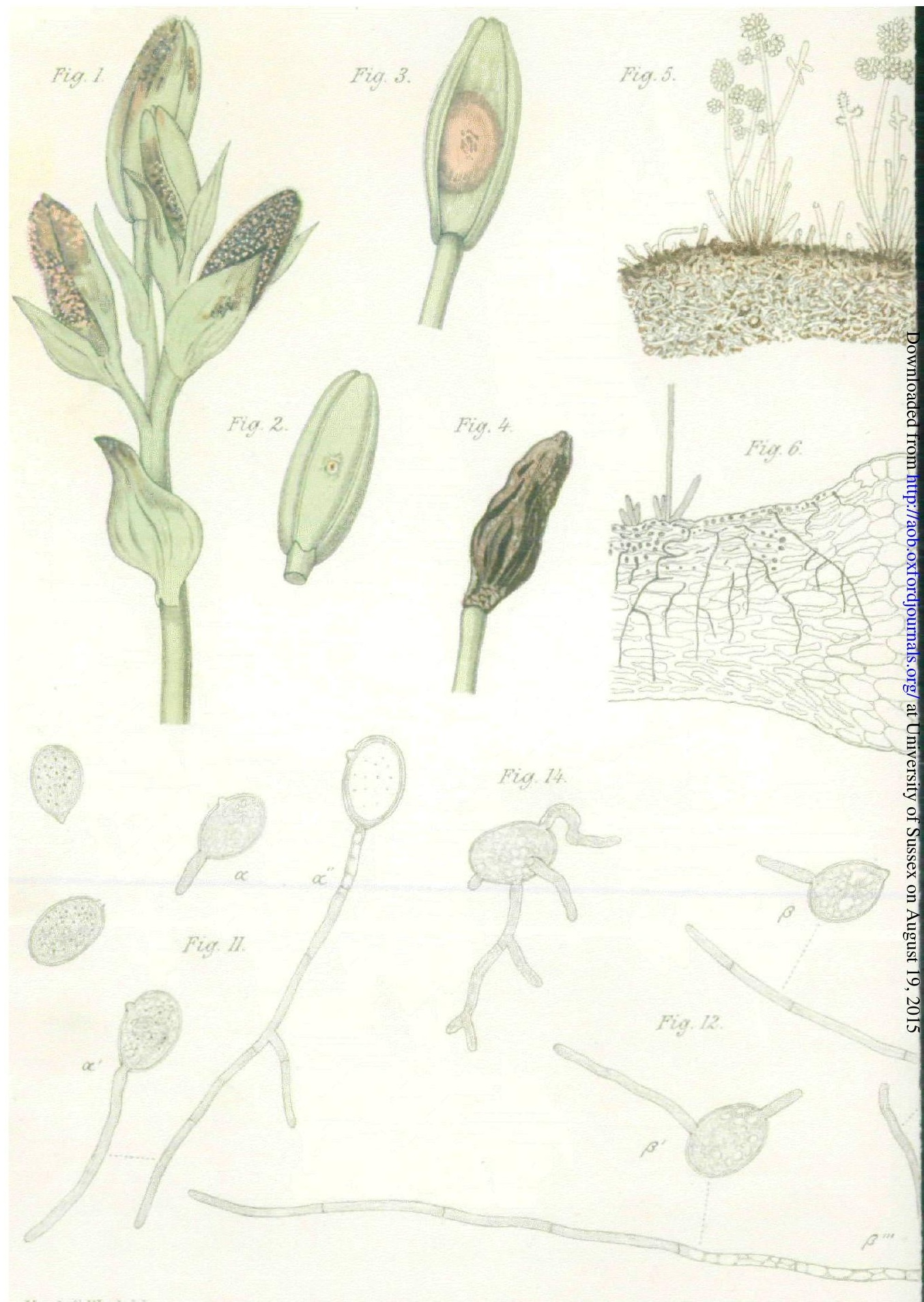


VoL.II, PL.XX.
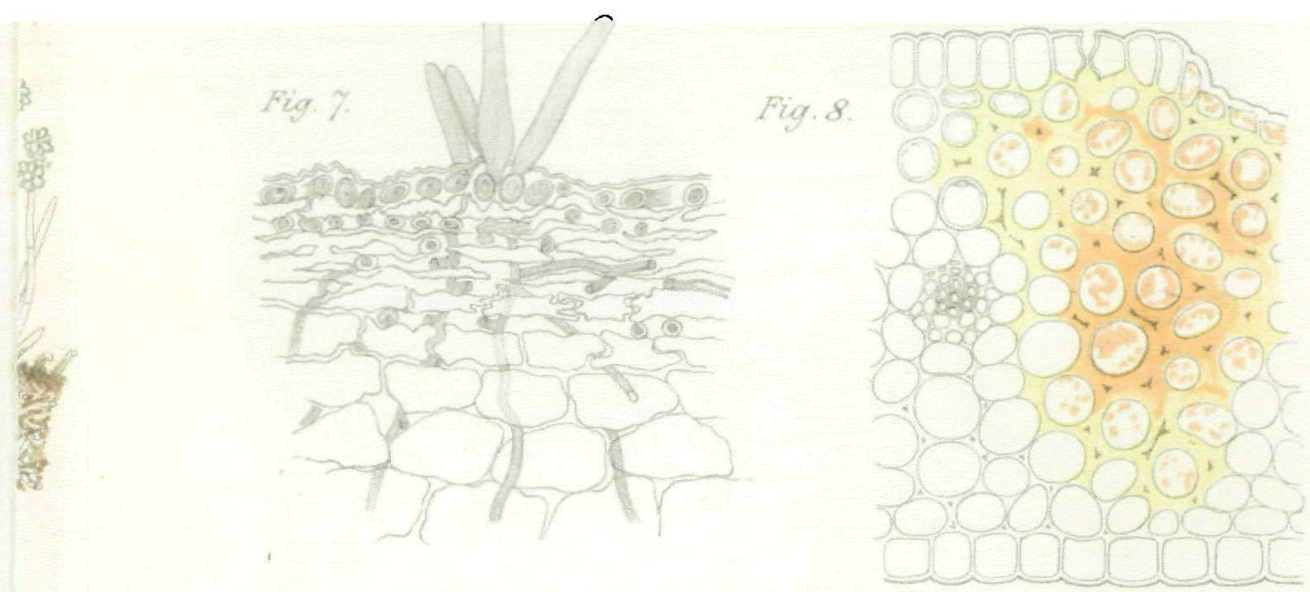

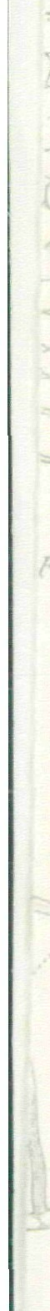

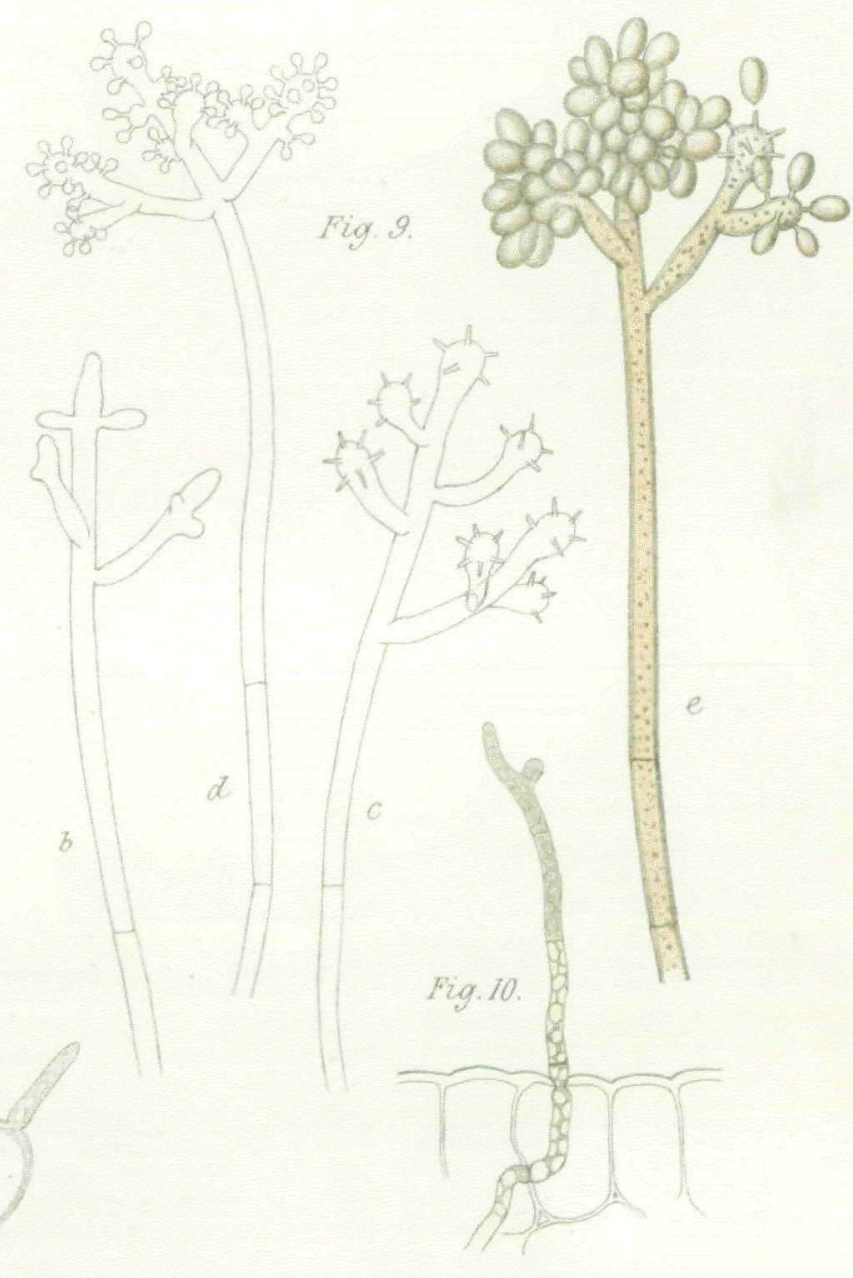

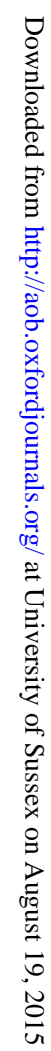

Univergity Press, Oxford 
Annats of Botany

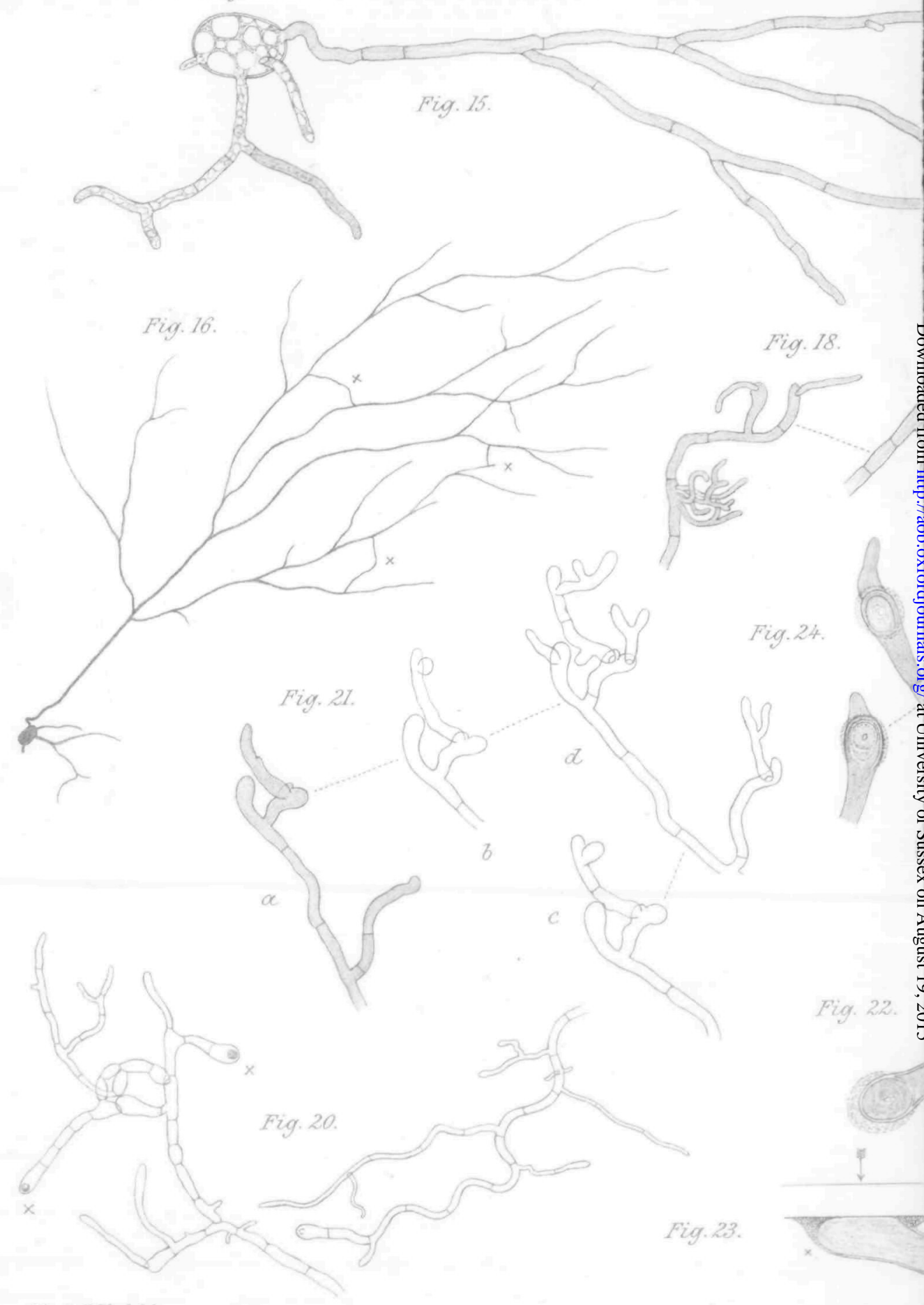

Marsinall Ward del

MARSHALLWARD. - ON A LILY-DISEASE. 
VoL.II, PU.XXT.
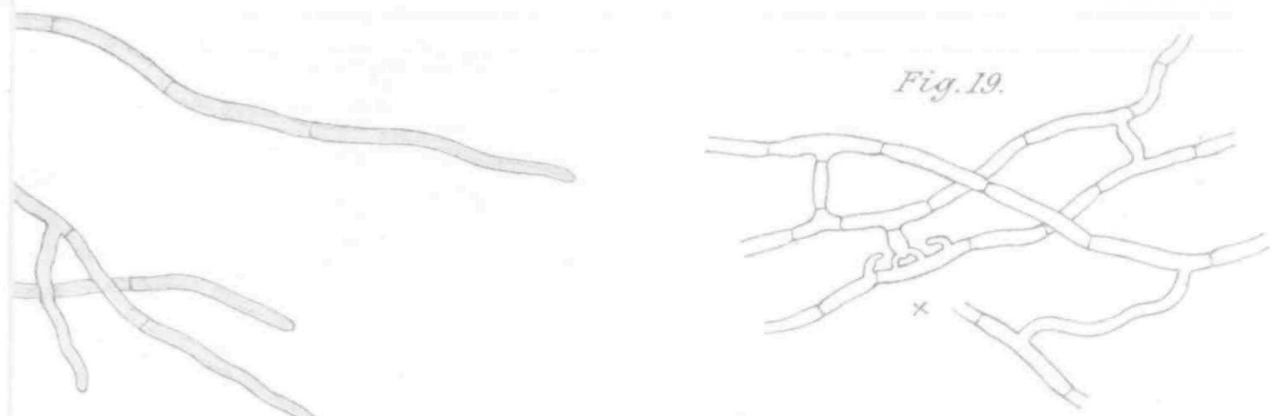

Fig. $1 \%$
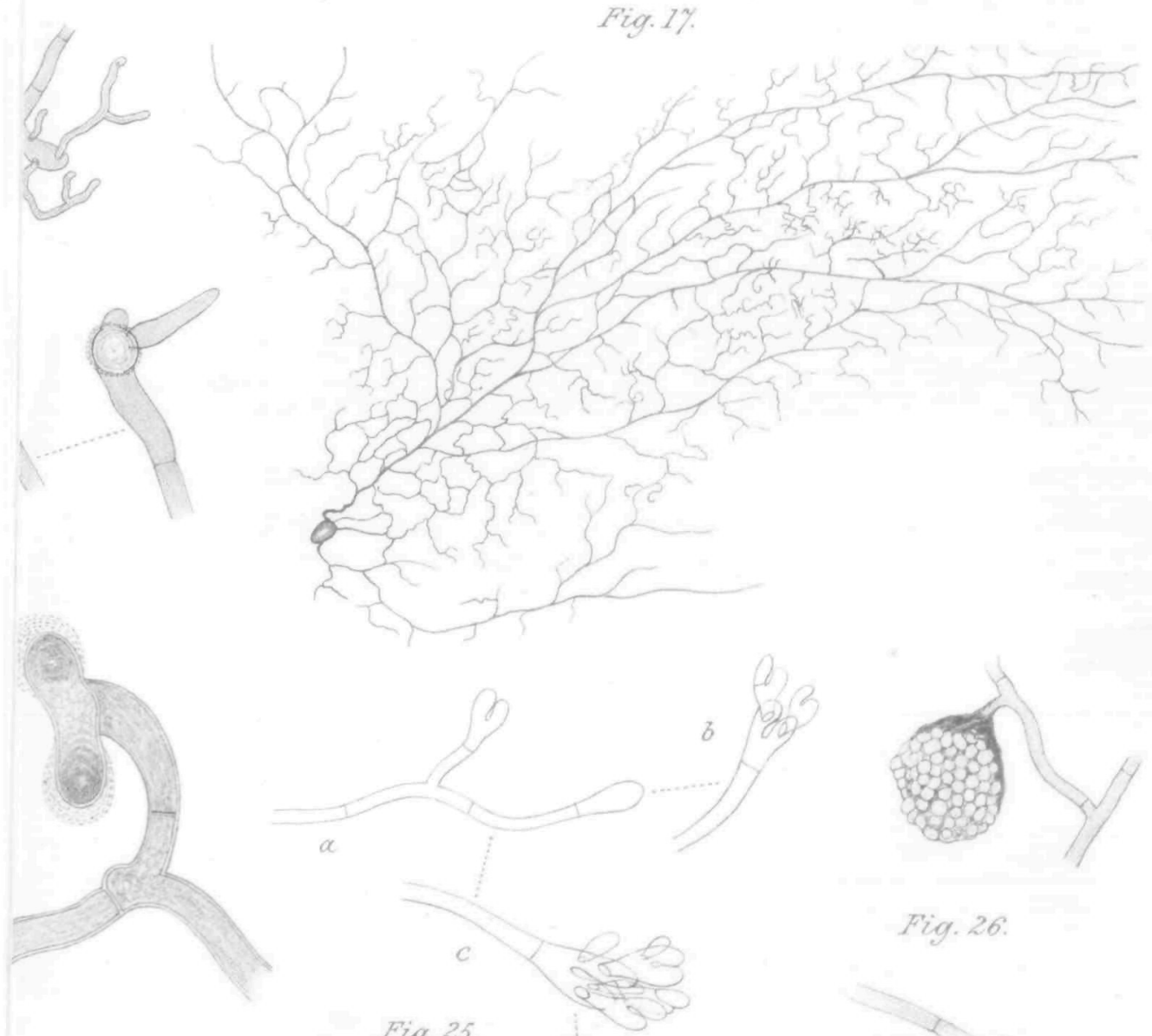

Fig. 26.

Fig. 25
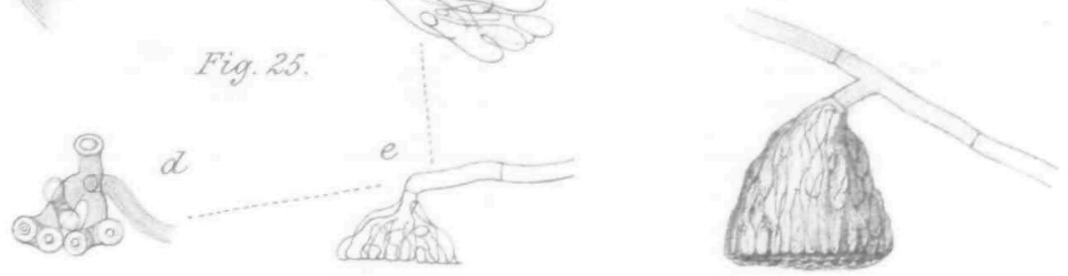

University Press, Oxford.

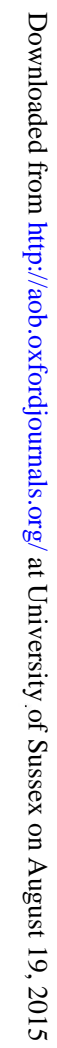




\section{Marshall Ward.-On a lily-disease.}

Fig. 32. A small culture of the fungus, from a single spore sown in a hanging drop: the medium was partially exhausted Pasteur's solution, and the culture was five days old. The original spore could still be seen in the meshes at $s$ : the mycelium developed was not very large, but otherwise normal. Having nearly exhansted the food-materials, it passed over to the formation of conidiophores $(c, c)$, seven of which are nearly completed. On the branches of the hyphae, especially at the edges and surface of the liquid where they are nearer to the air, numerous brilliant bubbles of gas are to be seen attached to the hyphae: this is a well-known phenomenon in such cultures, especially preceding the development of aërial conidia. It is, of course, not necessary to remark that these bubbles have nothing to do with the droplets extruded from the tips of hyphae described below. Zeiss A, oc. 2.

Fig. 33. Small conidiophores from a similar culture to the last, showing how the conidia may arise on short lateral branches, as well as on the normal erect conidiophores. The small branch $(x)$ below the conidia grew out later into a secondary conidiophore similar to that in Fig. 26. Zeiss D, oc. 4.

Fig. 34. One of the conidiophores observed during its whole course of development. At 4.45 p.m. the erect hypha ( $I)$ was beginning to swell at the apex, and to put forth two branches below; these grew larger, and at 5 p.m. were as in 2. Half-an-hour later (i. e. at $5.30 \mathrm{p}$.m.) a number of small projections appeared like bright points on the swollen portions (3), and at 5.45 were seen to be peg-like outgrowths (4), which gradually lengthened, and commenced to swell at the ends ( 5 , drawn at 6.5 p.m.) The swelling ends of these pegs (sterigmata) soon assumed the ovoid form of young conidia, and at 6.15 presented the appearance shown in 6 . The development was now very rapid; 7 was drawn at 6.25 , and by 6.40 the conidia were practically mature $(8)$, the only further changes observable being the darkening in hue of the ripening conidia, which now drop off at the slightest vibration. The specimens were from a mycelium growing in Pasteur's solution, the solution having been again boiled; only the outlines are drawn, but it will be understood that all parts are filled with brilliant nearly homogeneous protoplasm. Zeiss D.

Fig. 35. Similar culture to the last, but showing the air-bubbles which are so common on the developing conidiophores, $a$, at 4.40 p.m. : $b$, at 5.25 p.m. Zeiss $\mathrm{D}$.

Fig. 36. An aërial branch from a culture such as Fig. 21 , showing the incrustation of minute crystals of calcium oxalate on the cell-walls. Zeiss D, oc. 2.

\section{PLATE XXIII.}

Fig. 37. A conidiophore from a 6 days' culture in Pasteur's solution, showing the formation of a second head of conidia from a branch below the one first - developed. The culture was the same as that from which Fig. ${ }_{5}$ was taken. The characteristic brownish colour of the quite mature spore and conidiophore has been omitted. Zeiss $D$, oc. 2.

Fig. 38. Branched conidiophore abundantly produced in the damp air of a culture-chamber: the mycelium had been growing for 14 days in a drop of raisin-extract, to which Pasteur's solution was added later. It should be noticed that the whole is a sympodium, each successive tuft arising at the end of a branch from beneath the one next below. Cf. Fig. $33 \times$ and Fig. 37. Zeiss B, oc. 2.

Fig. 39. A young conidiophore from a culture in partially exhausted Pasteur's

$$
\text { C } \mathrm{c} 2
$$


solution. At Ir.3o a.m. it presented the appearance shown in $a$, having six septa and a long growing segment above the sixth septum: at 3.20 p.m. this apical segment alone had grown to double its former length and had formed two new septa, as shown in $b$. Zeiss $\mathrm{D}$, oc. 4 .

Fig. 40. Further preparations giving some information as to the growth of the filaments. In $a$, the hypha lay just above a very thin section of epidermis, at 2.55 p.m. At 3.5 p.m. the tip of the hypha had moved forward as shown in $b$ : at $3.30 \mathrm{p} . \mathrm{m}$. the tip had progressed further still, having passed over the distance shown in $c$, and a small lateral branch had begun to form below. A comparison of the figures suggests that the apex described a slightly sinuous course, or very open spiral: it will be understood that the section of epidermis (part of a much larger piece) lay in a deeper plane. Zeiss $D$.

Fig. 4I. The hypha $a$, crossing the one $b$, was in the position figured-relative to the diamond-shaped intercellular space towards which its tip is pointing-at 3.2 p.m., and it traversed the distances marked by $x \times$ in ten minutes, reaching the first $x$ at 3.7 , and the second $x$ at 3.12. Zeiss D.

Fig. 42. Three characteristic groups of terminal branches of a mycelium grown for a week in Pasteur's solution: the whole mycelium was produced from one spore At the points marked $x$, the ends of the hypha are seen to give off each a small cloudy drop. This, when first excreted, is a transparent, apparently mucilaginous drop, with very minute brilliant granules in it : as it ages, however, in a few hours it becomes more granular and has a yellowish hue. It gives proteid reactions, and the evidence goes to show that it contains a ferment which liquefies cellulose. Zeiss D.

Fig. 43. Similar excretions of drops from a culture in thin extract of raisins. Note the vacuolation of the hyphae. Zeiss D.

Fig. 44. Similar excretions of drops from hyphae of a large culture in Pasteur's solution (seven days after sowing). The preparation was taken from the edges of the large circular mycelium, which was a millimetre thick and nearly a decimetre in diameter: the excretion is much more copious in such pure cultures in flasks, with plenty of air and food-materials. Zeiss D, oc. 4 .

Fig. 45. One of the free hyphae of a strong culture shown in process of excretion of the drop. At first the protoplasm is bright and almost homogeneous $(I)$; when the drop commences to exude, the protoplasm has been getting more and more vacnolated and granular (2); and this increases (3); until at length there may be very little protoplasmic content left (4); and the end may even collapse; but it frequently happens that the hypha goes on growing in the stage 3, either putting out a bud-like outgrowth which becomes a branch, or itself going on growing. Zeiss J, oc. 3 and 4 .

Fig. 46. Preparation showing the infection of the epidermis of a lily-bud. The conidium was placed on the bud in a drop of distilled water two days previously: it had germinated, and the tip of the longer tube attached itself closely to the cuticle and then discoloured and pierced it, the contents of the spore passing into the tube. The epidermal cells are only in outline. Zeiss D, oc. 2.

Fig. 47. Similar preparation, with two infecting conidia: in the upper one the whole of the protoplasm of the spore bas already passed into the infecting tube, in the lower one some is still retained. Forty-eight hours' germination. As shown by 
Annats of Botany

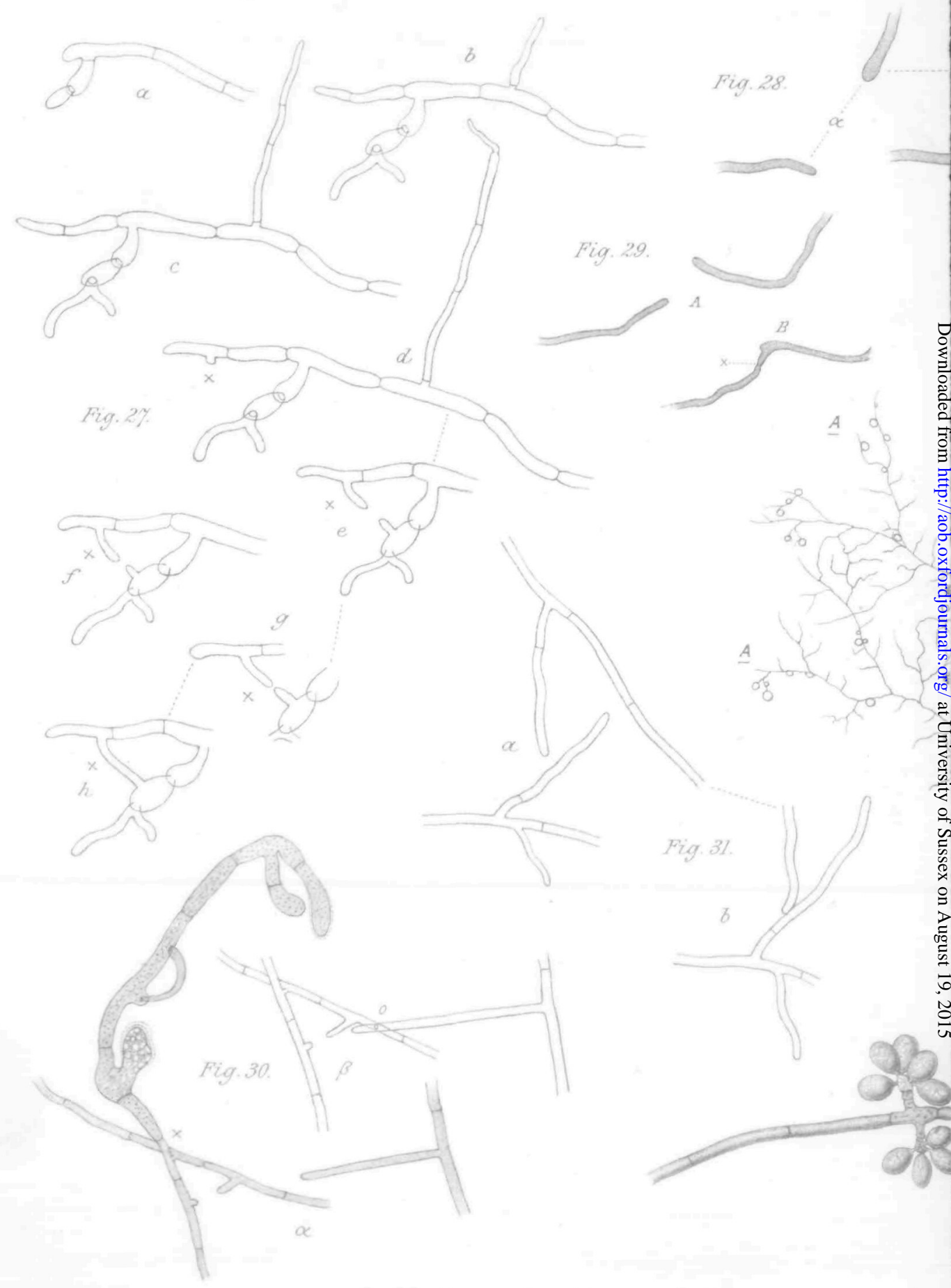

Marshall Ward del.

MARSHALLWARD. - ONA LILY-DISEASE. 
Vol.II, PI XXII.
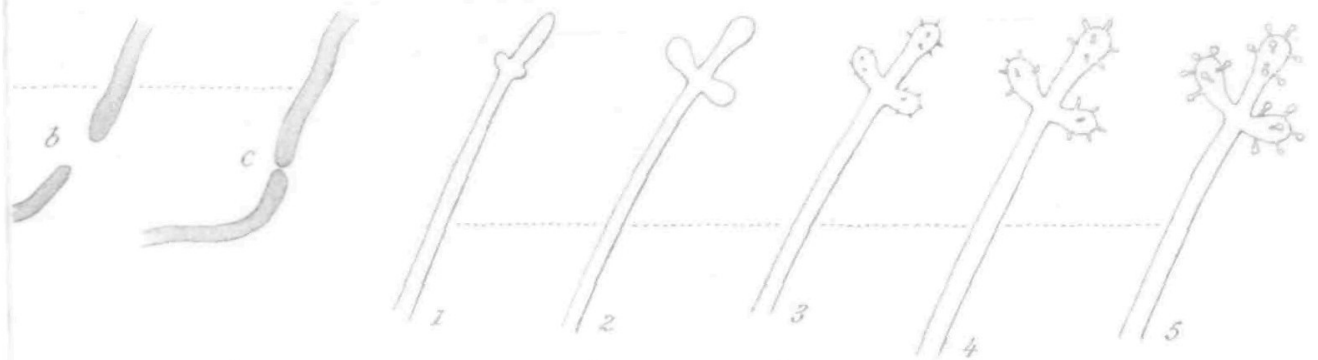

Fig. 34 .

Fig. 32
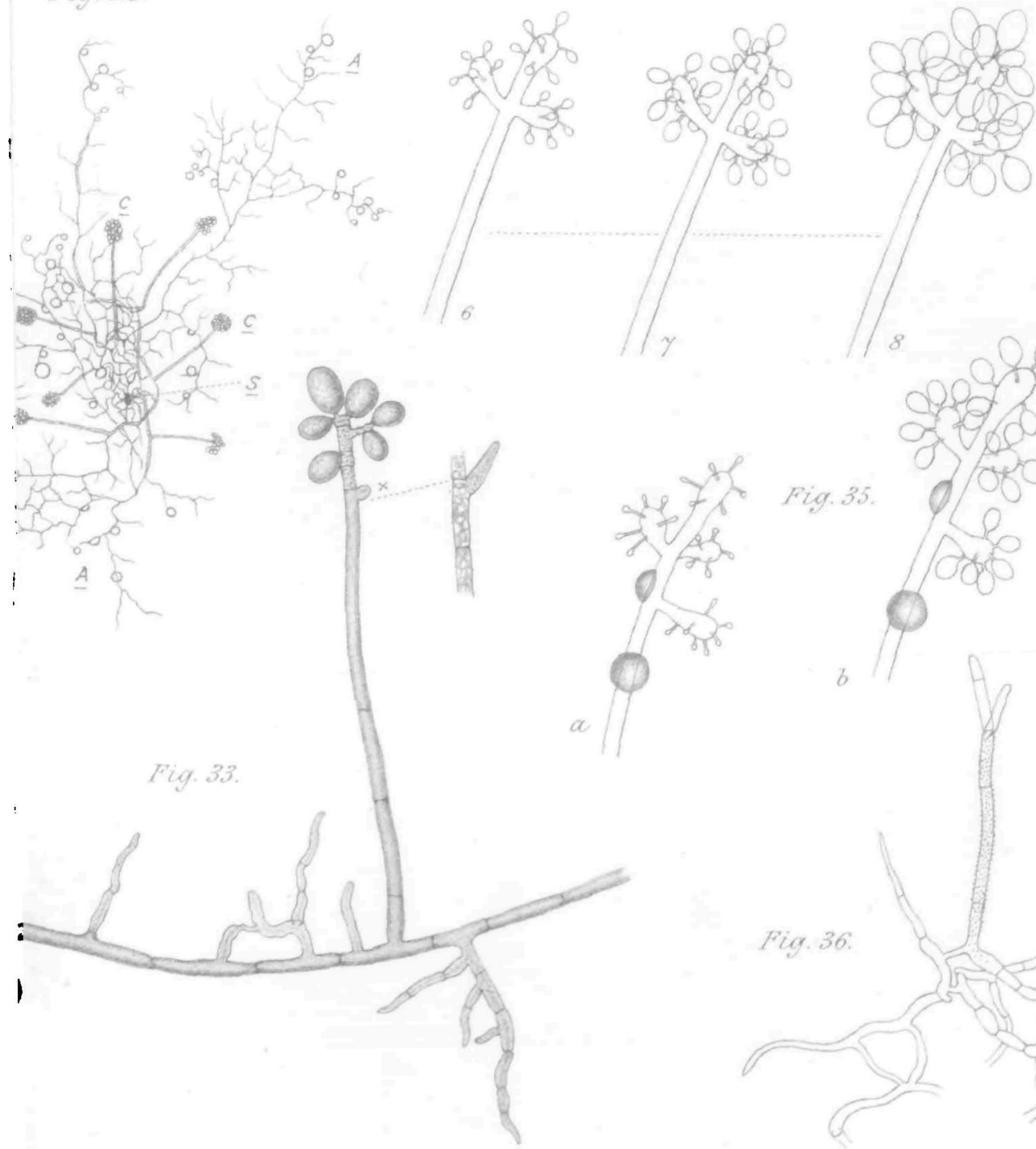

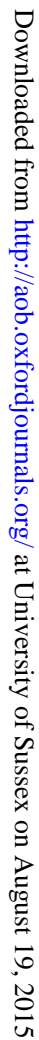

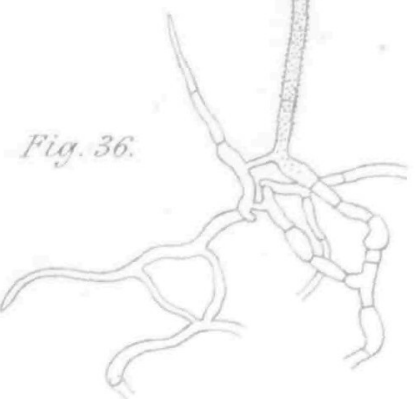

Thiversity Press, Oxford. 


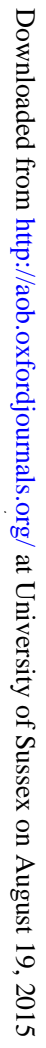




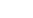


Annals of Botany
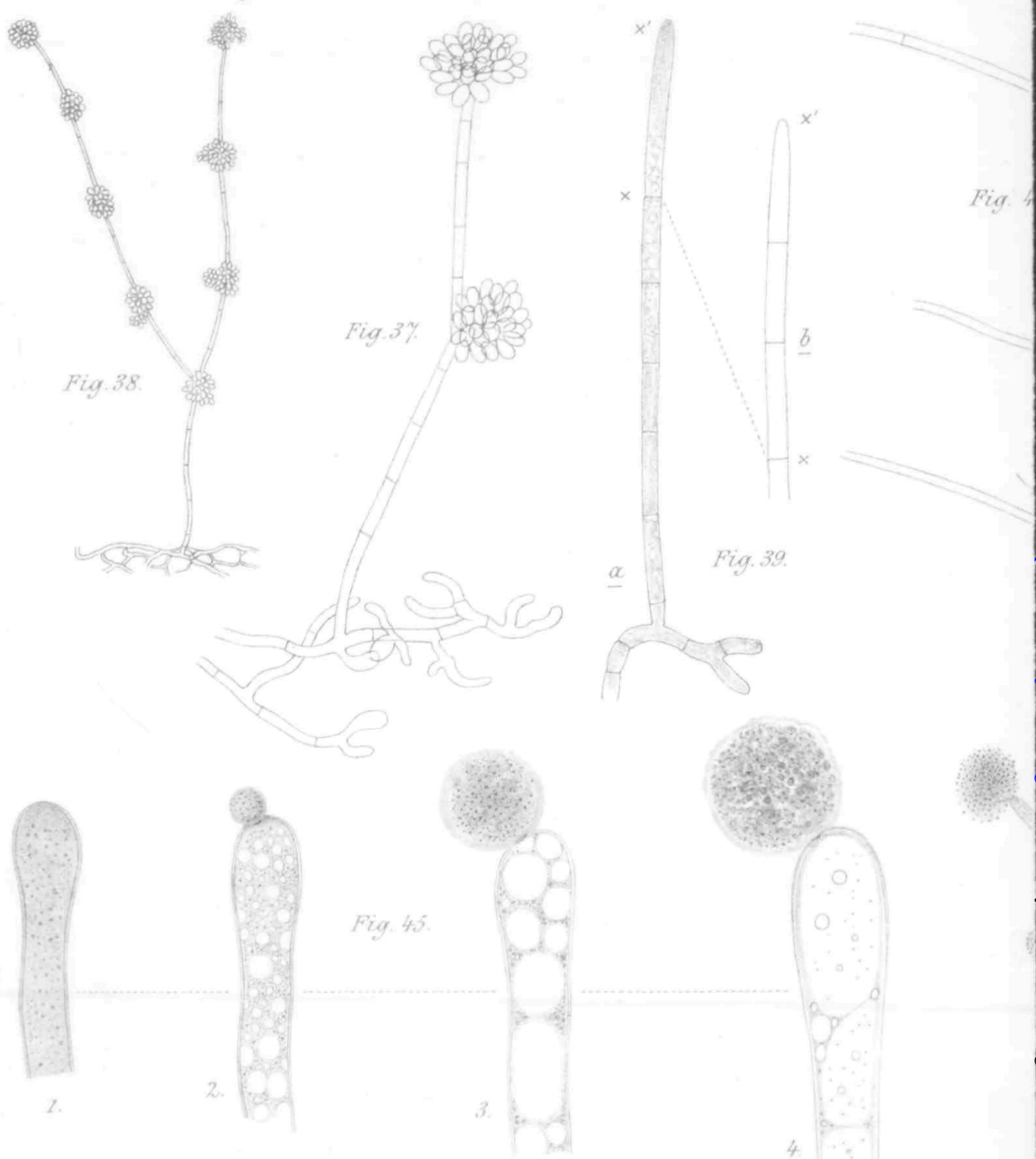

Fig. 39

Fig. 46 .

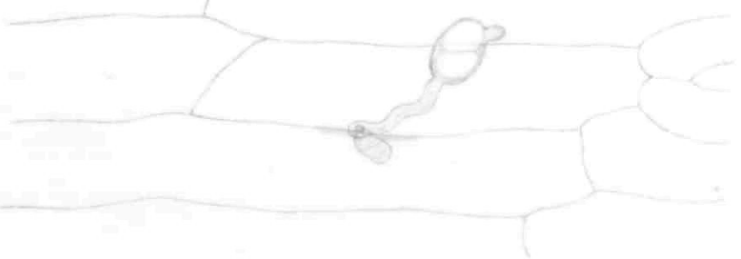

Fig. $4 \%$

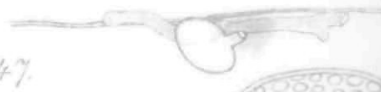

Marshall Ward del.

MARSHALL WARD.- ON A LILY-DISEASE. 

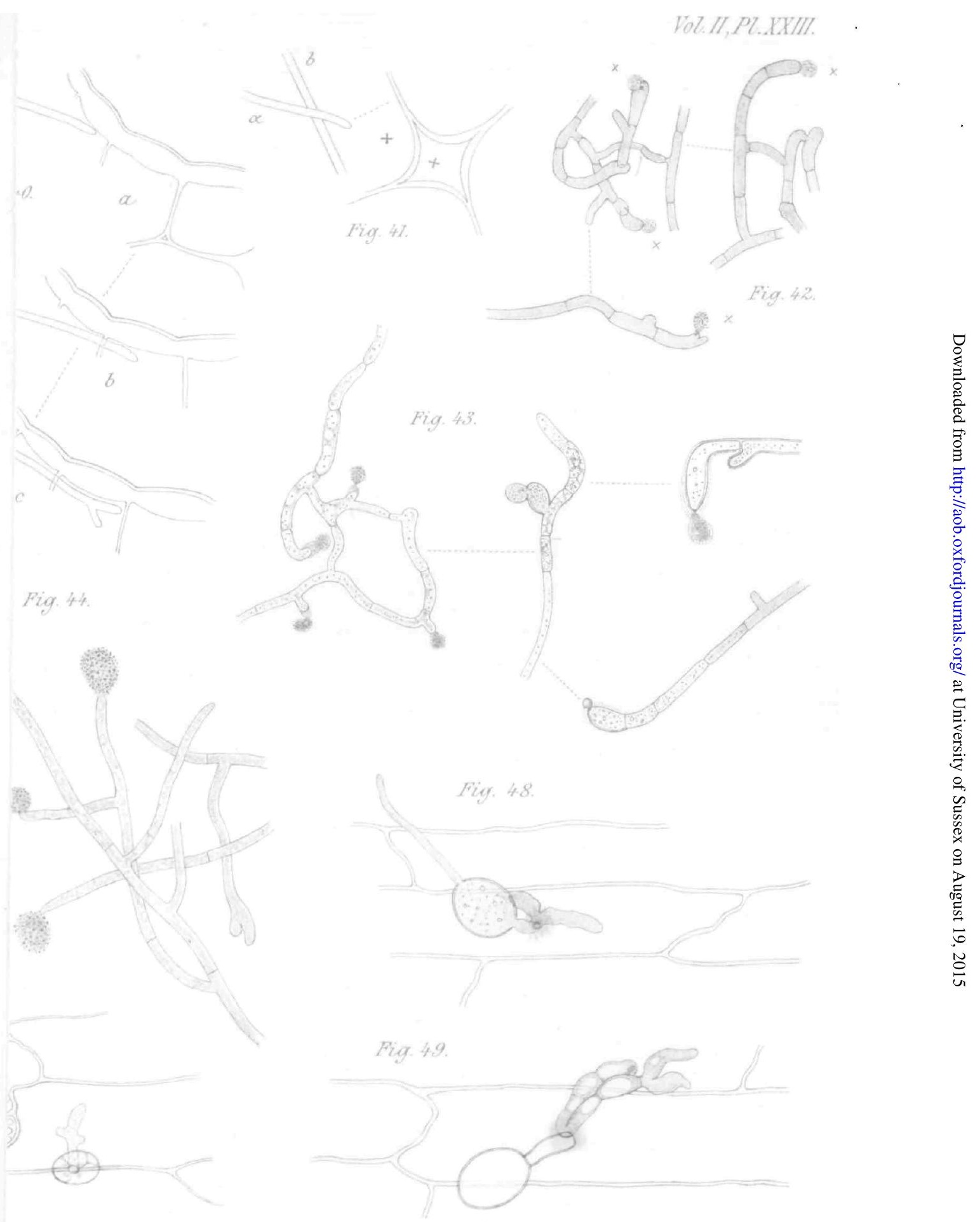

University Press, Dxford. 

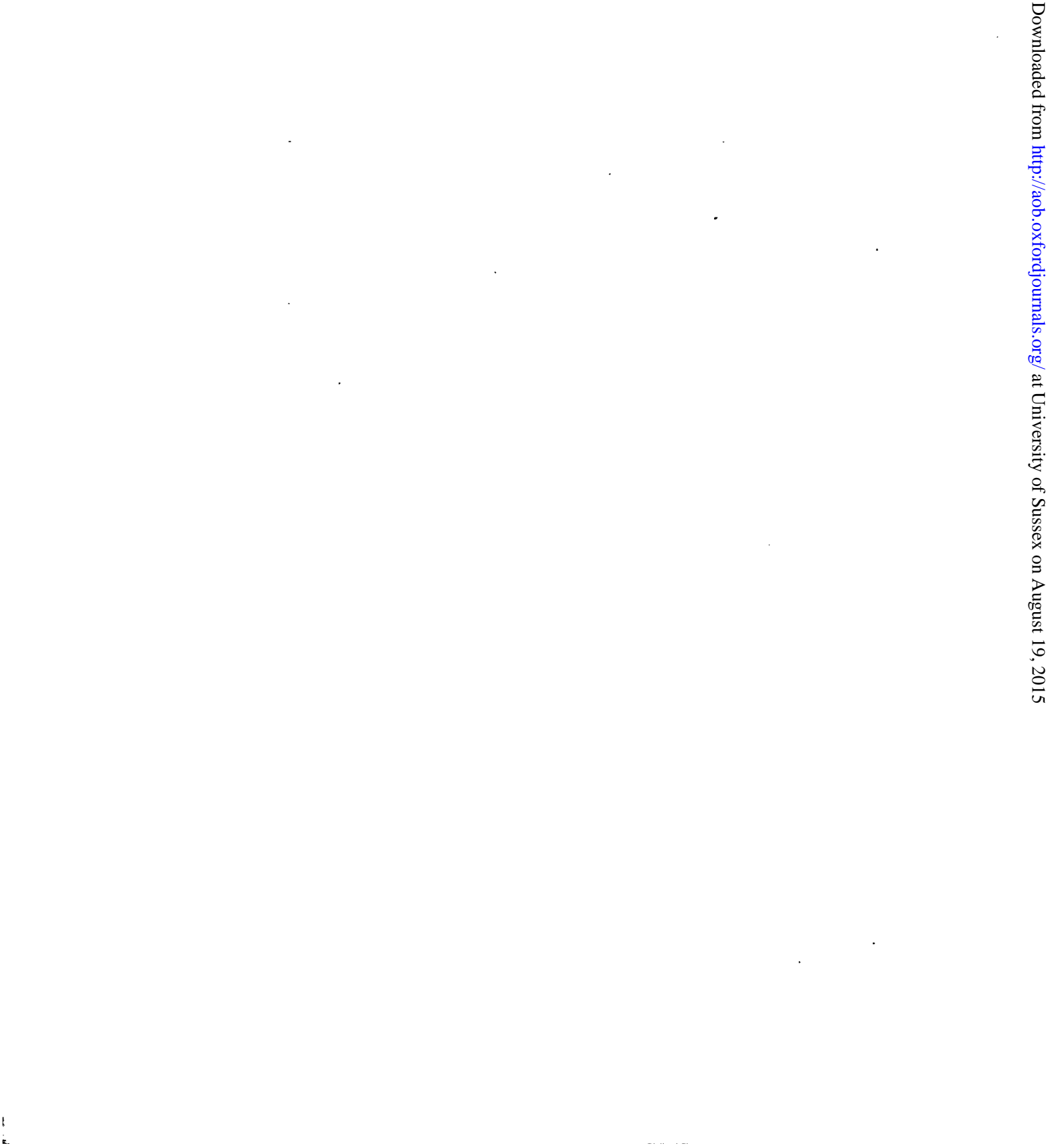


\section{Marshall Ward.-On a lily-disease.}

later preparations, these infecting tubes are running in the substance of the outer walls of the epidermal cells, just beneath the cuticle. Zeiss D, oc. 2.

Fig. 48. Similar preparation, but the conidium lay in a drop of dilute Pasteur's solution on the epidermis, and has thrown out a long thin hypha outside, in addition to the infecting tube below the cuticle. The spore still retained some protoplasm. Zeiss E, oc. 4 .

Fig. 49. Similar preparation to the last, but the whole of the protoplasm has already passed into the infecting tube, which has become branched and septate. This preparation and the last were treated with chloral-hydrate before drawing. Zeiss E, oc. 4.

\section{PLATE XXIV.}

Fig. 50. Preparation showing a not uncommon mode of infection. The spore had germinated on the outside of the epidermis, and rapidly produced dense tufts of branching hyphae which make their way simultaneously into the tissues: the cell-walls around are all gelatinised, and turning brown. The preparation was made by cutting off the epidermis with the razor, and viewed from within. If seen in section (at right angles to the plane of the figure) the epidermis would be found sunk in, and turning brown, this could not be shown in the drawing. Zeiss D.

Fig. 5I. Vertical section through a lily-bud with a 'disease spot' in the condition shown in Fig. 2. The epidermis and cuticle, together with underlying cells, have collapsed and turned brown: at first sight there are no signs of a fungus at this stage, but if such a section is carefully swollen by being treated with very dilute ammonia or chloral hydrate, the gelatinised cell-walls are found to have the fungus embedded in their substance. Zeiss $D$.

Fig. 52. A similar section to the above, but which has been swollen by holding it for a minute over an open bottle of ammonia hydrate. It is then seen that the walls of the epidermal cells and several subjacent cells are completely gelatinised and broken down, and that the fungus-hyphae are rampant in the mucilage. The destructive action is also seen to extend for some distance into the walls of neighbouring cells, as indicated by the yellow and red-brown hues which the destroyed walls assume. Zeiss $D$.

Fig. 53. Similar preparation to the last, but the section was taken through the pedicel, and the spot was in a slightly less advanced stage. The section was observed in water, in which the preparation (cut fresh) was laid: little can be made out beyond the fact that the cells are destroyed and the cuticle sunk; but it may be noticed that $I$ had observed and drawn a sort of irregular dark mass, looking like a slight thickening of the cuticle about the middle of the depression -this was no doubt the collapsed remains of the spore.

In Fig. 54 the same section is shown after treatment with extremely dilute ammonia, and we now see that branched infecting hyphae were all the time embedded in the contracted mucilage produced by the destruction of the cell-walls : moreover, the empty spore which gave rise to these hyphae was still attached, and assumed its normal position after swelling in the ammonia. Again, and very clearly, it is seen that the destruction is extending into the walls of cells at a distance from the hyphae (cf. Fig. 8): it seems difficult to imagine how this can occur otherwise than by the diffusion of a soluble ferment, and investigation 


\section{Marshall Ward.-On a lily-disease.}

shows that this explanation is no doubt the correct one. It will be noticed that the cuticle is not dissolved. Zeiss D.

Fig. 55. Part of a section through a lily-bud (perianth), on which the conidia had been allowed to germinate for three days, and which was thereby infected, as shown in Figs. 46-49. The section was cut from a bud which, after infection as said, was hardened in picro-nigrosin, and then absolute alcohol: it was then laid in glycerine, and held for a minute over the ammonia bottle. The left-hand guard-cell of the stoma and the whole of the section on the left were intact; but the five epidermis cells to the right of the stoma had collapsed under the pressure exerted by their gelatinised cell-walls, in the substance of which the hyphae are running. Further to the right, again, the cells are intact. The swelling action of the hyphae is beautifully seen in the walls below the right-hand guard-cell. The swollen cell-walls in such sections still give a faint blue with chlor-zinc-iodine. Zeiss E, oc. 4.

Fig. 56. Part of a similar preparation, perhaps slightly less advanced. All the essential features are as before. Zeiss E, oc. 4.

Fig. 57. Two stages showing the piercing of a cell-wall by the tip of a byliha. From a mycelium which had been growing for four days in a hanging drop, containing a minute section of a piece of lily-bulb. The hypha was observed to meet the cell-wall nearly at right angles: contact was established at 4.35 , as seen in $a$. At 4.45 , as seen in $b$, the tip of the hypha had dissolved a minute hole through the wall, passed through, and bulged out to its normal size on the opposite side. Zeiss D.

Fig. 58. Another case of the same kind, observed on Ang. 4. At 2.55 p.m. the hypha, which bad traversed a drop of culture fluid (water containing a piece of lily-bulb), came vertically in contact with a cell-wall (a). The hypha was growing rapidly, and in three minutes its tip was seen to be deflected slightly $(b=2.58$ p.m.): this deflection increased-c was drawn at 3.0 p.m., and $d$ at 3.2 p.m. A.t 3.7 p.m., the tip had obviously sunk into the substance of the cell-wall, which was swelling at the point of contact $(e)$ : the swelling of the wall and the sinking in of the tip of the hypha increased, and at 3.15 the tip of the hypha was nearly through, as shown at $f$. At $3.24(g)$ a minute, bright, drop-like protuberance was being put forth on the other side of the cell-wall : this was a bad-like outgrowth continning the onward growth of the hypha, as seen at $h(3.28$ p.m.) and $i(3.30)$. All Zeiss D, oc. 4 .

Fig. 59. Piece of thin transverse section of pedicel of lily after lying six hours in boiled extract from the fungus: the extract was made by pounding in a mortar a flask culture (in Pasteur's solution) of the fungus, with a little distilled water. Zeiss D.

Fig. 60. A similar preparation, but which had lain for six hours in the unboiled extract from the fungus. Even after one hour, the cell walls were observed to be swollen, and in six hours they were rapidly becoming disorganised: they still gave the blue reaction with chlor-zinc-iodine. Zeiss D. 
treats of Botany
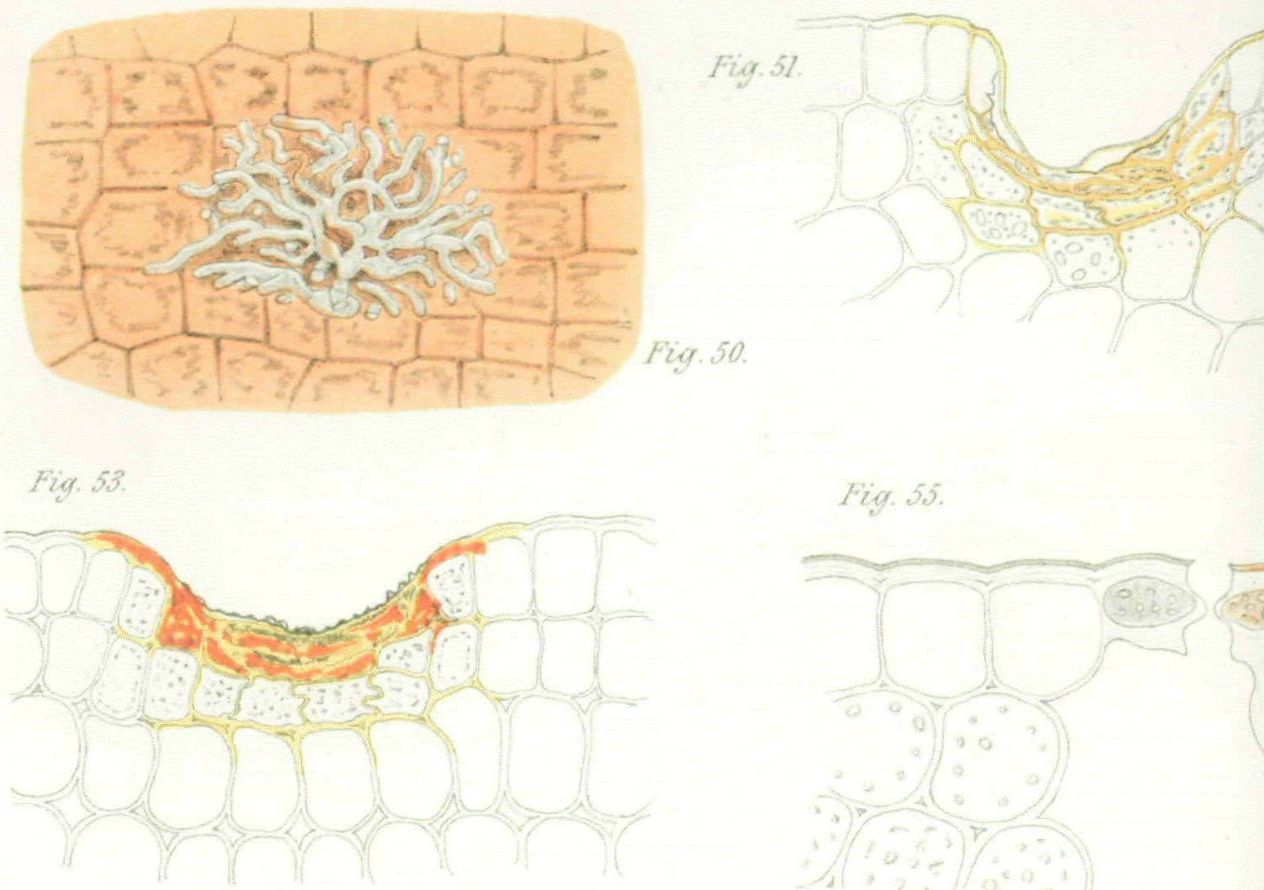

Fig. 55
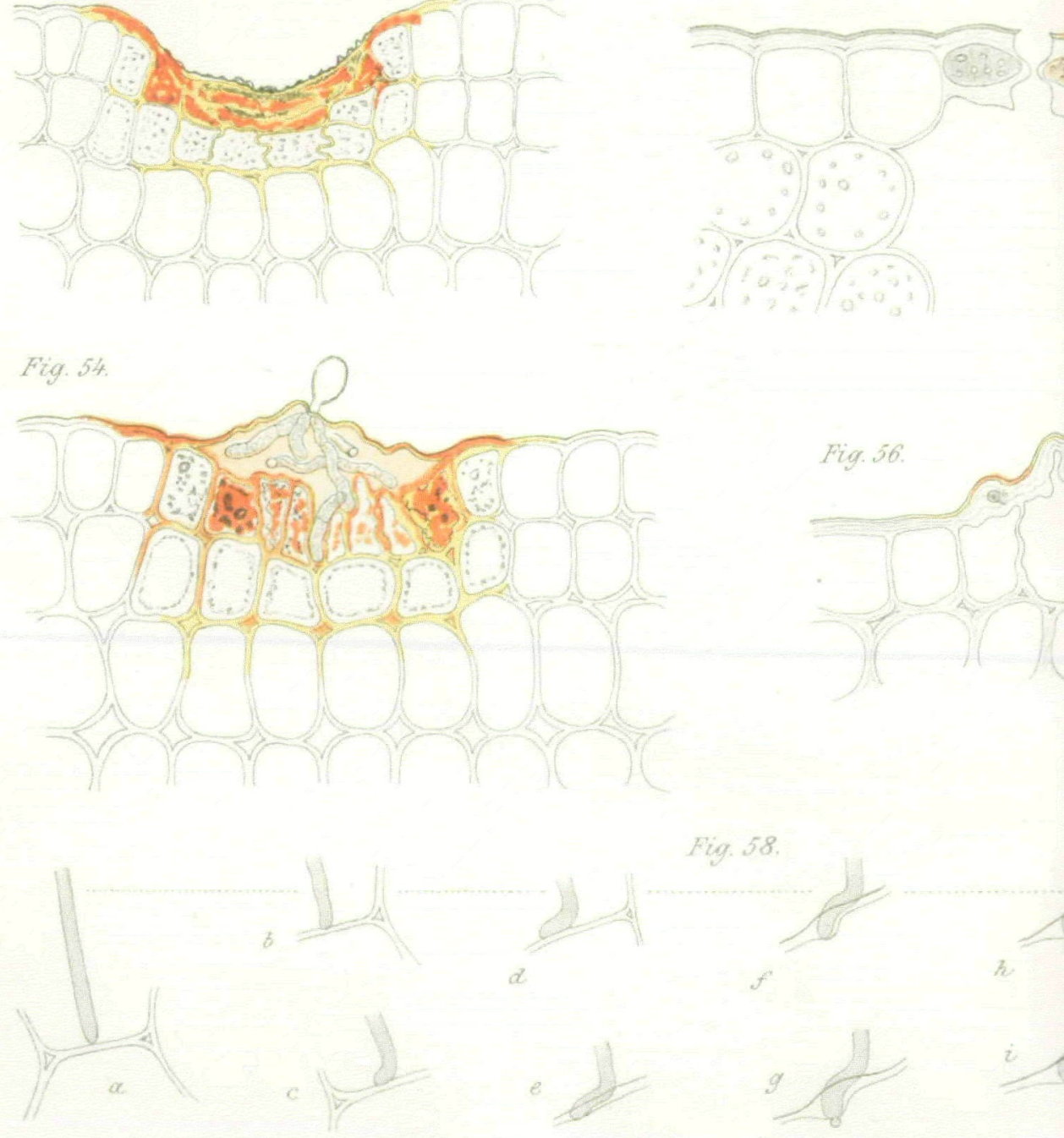

Fig. 58 .

Fig. 56.

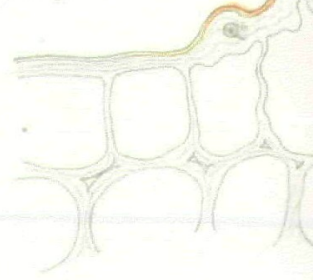

a
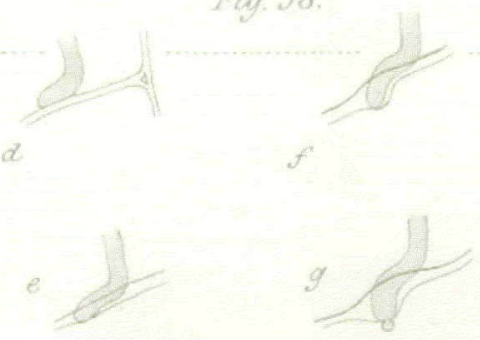

i

Marshall Ward del.

MARSHALL WARD. - ON A LILY -DISEASE. 

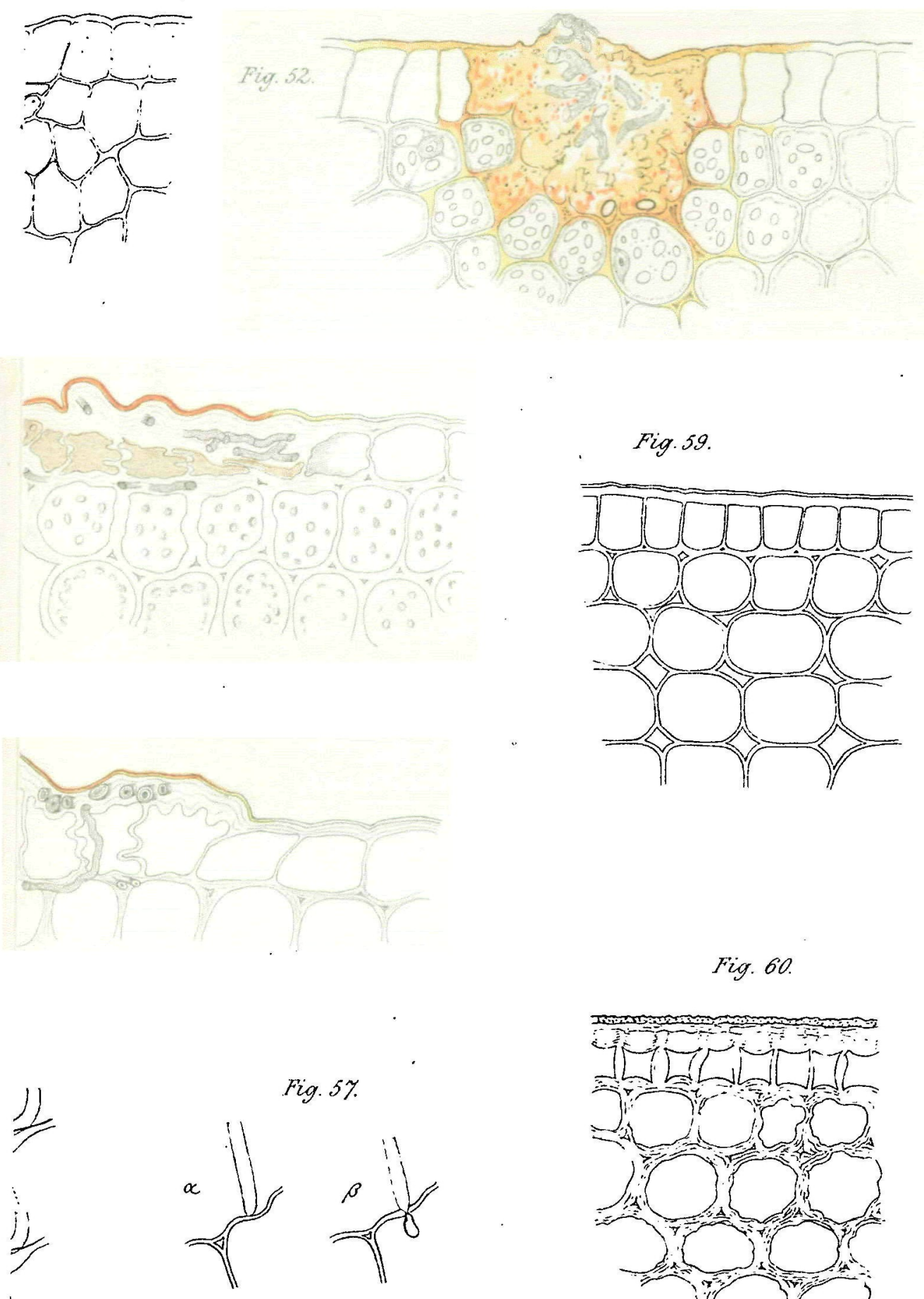

Fig. 60.

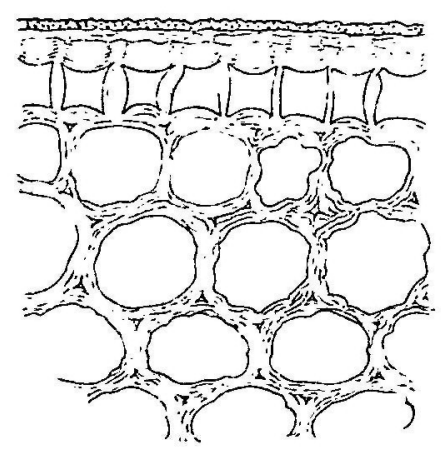

University Press, 0xforã. 
A

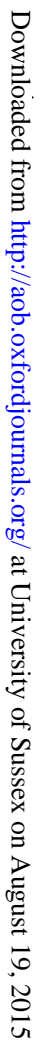

$\vdots$ 